\title{
The Competition between the Dimerization of Radical Anions and their Reactions with Electrophiles
}

\author{
Ole Hammerich* and Merete Folmer Nielsen*
}

Department of Chemistry, University of Copenhagen, Symbion Science Park, Fruebjergvej 3, DK-2100 Copenhagen, Denmark

\section{Dedicated to Professor Lennart Eberson on the occasion of his 65th birthday}

\begin{abstract}
Hammerich, O. and Nielsen, M. F., 1998. The Competition between the Dimerization of Radical Anions and their Reactions with Electrophiles. - Acta Chem. Scand. 52: 831-857. (C) Acta Chemica Scandinavica 1998.

The reactivity of the radical anions derived from cinnamic acid esters decreases in radical ion-radical ion dimerization and increases in protonation when the esters become less easy to reduce. This is reflected by plots of $\log k$ vs. $E^{\circ}$ $\left(\log k_{\text {dim }}\right.$ or $\left.\log k_{\text {prot }}\right)$ that are linear, but with slopes of different sign. Results obtained by AMI calculations show that the unpaired electron density, $c_{\text {Somo }}^{2}$, at $\mathrm{C}-3$ and the negative charge, $-q$, at $\mathrm{C}-2$ vary in a fashion similar to that observed for $\log k_{\text {dim }}$ and $\log k_{\text {prot }}$, respectively.

The available kinetics and product data for other series of radical anions are reviewed and trends similar to those observed for the cinnamate radical anions are apparent in most cases.

More insight into the possible relationship between the electronic properties of radical anions and their reactivity was obtained through AM1 calculations for seven series of model compounds (monosubstituted ethylenes, 1,2-disubstituted ethylenes, monosubstituted benzenes, 1-substituted 2,6-di-tert-butylbenzenes, 9-substituted anthracenes and esters of acrylic and cinnamic acid) encompassing a total of 93 compounds. Calculations were also carried out for the much smaller number of radical anions for which experimental data are available. The results show that the introduction of an alkyl or alkyl-like substituent, or a $\pi$-type substituent that is not in conjugation with the parent $\pi$-system, gives rise to only a small electronic perturbation and in those cases $c_{\text {somo }}^{2}$ and $q$ at the atoms of interest are essentially linearly related with the adiabatic gas phase electron affinities, $\Delta \Delta H_{\mathrm{f}}=\Delta H_{\mathrm{f}}^{\text {radical anion }}-\Delta H_{\mathrm{f}}^{\text {substrate }}$, representing the ease of reduction of the substrate. It is also found that the formation of the new $\mathrm{C}-\mathrm{C}$ bond during dimerization does not as a rule involve the carbon carrying the highest unpaired electron density and, similarly, protonation does not as a rule take place at the carbon carrying the highest negative charge. For example, for the 9-substituted anthracene radical anions the highest unpaired electron density is located at the carbon carrying the substituent (C-9), whereas dimerization takes place through C-10. The high values of $c_{\text {sомо }}^{2}$ at $\mathrm{C}-9$ are suggested to be the origin of the attractive forces leading to the $\pi$-complexes earlier proposed to be formed prior to the $10,10^{\prime} \sigma$-bond. The results obtained for the other series of compounds indicate that the formation of such intermediate $\pi$-complexes may be a general phenomenon.

Finally, the question of radical ion-radical ion (RR) versus radical ion-substrate (RS) mechanisms in reductive dimerizations is addressed.
\end{abstract}

\section{Introduction}

Radical ions are the primary intermediates in most organic electron transfer reactions, ${ }^{1}$ eqns. (1) and (2), including the majority of all electrochemical processes, ${ }^{2}$ and are formed also in many photochemical ${ }^{3}$ and conventional reactions. ${ }^{1,4-6}$ In addition, radical ions are effective catalysts for a number of processes, most notably cyclo-

\footnotetext{
* To whom correspondence should be addressed.
}

additions, ${ }^{7}$ and are key intermediates in substitution reactions of the $\mathrm{S}_{\mathrm{RN}} 1$ type $^{8}$ and other chain reactions. ${ }^{9}$

$\mathrm{A}+\mathrm{e}^{-} \rightleftharpoons \mathrm{A}^{--}$

$\mathrm{A}-\mathrm{e}^{-} \rightleftharpoons \mathrm{A}^{\cdot+}$

As a result of the continuing interest in radical ion chemistry ${ }^{1-16}$ the characteristic reactions are now wellknown and many reaction mechanisms have been described in detail. The reaction types most frequently 
observed are summarized in Scheme 1, which for convenience is divided into two parts. The self-reactions, here defined as reactions that do not require the addition of a reagent to proceed and thus are difficult to suppress in cases where they are unwanted, are shown in Scheme 1A. Scheme 1B summarizes the reactions that in clean, inert solvents proceed only as a result of the addition of a reagent to the solution in which the radical ions are generated, or involve the solvent as a reagent. In all cases $\mathrm{X}$ is an atom or a group that during the later stages of the reactions may be eliminated as $\mathrm{X}^{-}$(for radical anions) or $\mathrm{X}^{+}$(for radical cations); $\mathrm{Y}, \mathrm{Y}^{-1+}$ and $\mathrm{Y}=\mathrm{Z}$ are neutral, charged and unsaturated reagents, respectively.

Only the first step is included for each case in Scheme 1 and is illustrated by an intermolecular reaction, except of course for the bond cleavage, but the A-units may obviously be linked in a remote position resulting in a similar set of intramolecular reactions. It is seen that this first step in all cases leads to a new intermediate which may be a radical, an ion or even another radical ion, and hence additional reaction steps are required on the way to stable products.

Scheme 1 illustrates that radical ions are indeed both radicals and ions. Some of the bond forming reactions, e.g., the dimerizations, are typical radical reactions, whereas others, e.g., the reactions between radical anions and electrophiles, or radical cations and nucleophiles, resemble those observed for other organic ions. It is also a characteristic that several reaction pathways are possible for a given set of starting materials and conditions, but most often they do not all proceed within the same time regime. Thus, the question of the competition between various pathways is usually reduced to the discussion of two or three possibilities, but even so it is not a simple task to predict which reaction occurs predominantly. As a result of this, much research is now devoted to the identification of the structural and other features that determine the reactivity of radical ions.

Our interest in radical ion reactivity dates back to the early seventies, when an important issue was whether the bond forming step in the reactions between radical

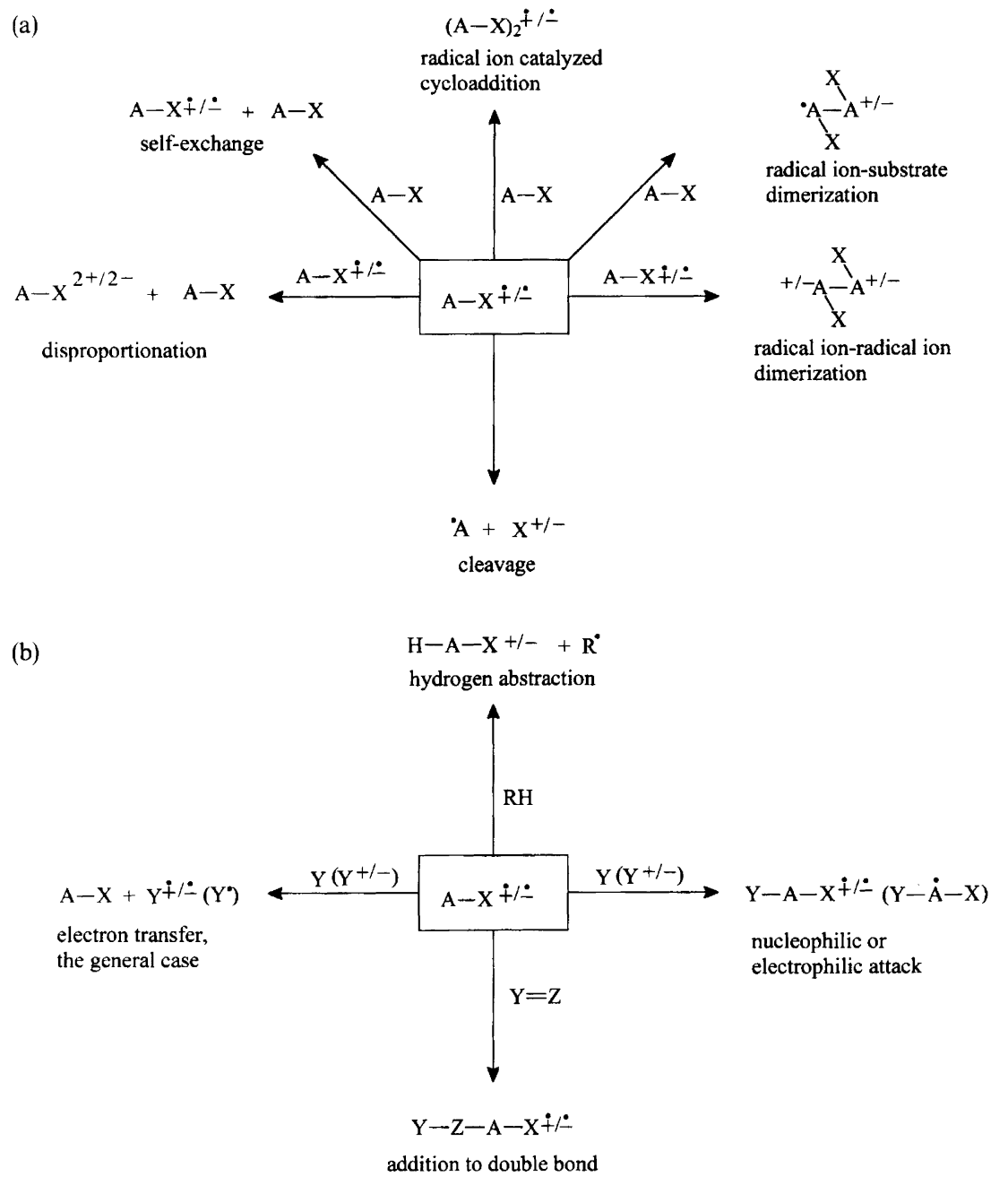

Scheme 1. 
cations and nucleophiles actually involves the radical cation or rather the more reactive dication formed by disproportionation. ${ }^{17}$ Since then we have continuously been inspired by the work of Professor Lennart Eberson, in particular his early studies of radical ion reactivity ${ }^{18}$ and his book on electron transfer in organic chemistry, ${ }^{1 \mathbf{a}}$ and it is a pleasure now to present some of our recent work on the occasion of his 65th birthday. More specifically, we address the structural features that govern the competition between the dimerization of radical anions and their reactions with electrophiles. We also discuss briefly the mechanisms for dimerization of radical ions in general.

\section{The reactivity of the radical anions of cinnamic acid esters in dimerization and protonation}

Recently, we have investigated the cathodic reduction of cinnamic acid esters ${ }^{19}$ and observed that the reactivity of the radical anions under conditions favoring either dimerization or protonation depends on the formal potential, $E^{\circ}$, for the substrate-radical anion redox couple. Since the results obtained provide a good background for a discussion of radical anion reactivity they are summarized in some detail below.

The electrohydrodimerization (EHD) of cinnamic acid esters in N,N-dimethylformamide (DMF). The cathodic reduction of cinnamic acid esters, $\mathrm{Ph}-\mathrm{CH}=\mathrm{CH}-\mathrm{COOR}$, in aprotic solvents such as DMF results initially in dimerization at C-3. This is followed by a Dieckmann condensation leading, after work-up, to the corresponding 2-alkoxycarbonyl-3,4-diphenylcyclopentanones (Scheme 2). ${ }^{19 a, 20,21}$ The yields from such $1 \mathrm{~F}$ reductions are often close to $100 \%$ and, in addition, the reaction is highly stereoselective giving exclusively the all-trans isomer corresponding to dimerization in the $( \pm)$ fashion only. ${ }^{21,22}$

Results obtained by cyclic voltammetry $(\mathrm{CV})$, derivative cyclic voltammetry (DCV) and linear sweep voltammetry (LSV) in DMF containing a moderate concentration $(0.28 \mathrm{M})$ of water demonstrated ${ }^{19 a}$ that the formation of the new $\mathrm{C}-\mathrm{C}$ bond involves the dimerization of two radical anions (Scheme 3), which in the transition state appear to be hydrogen-bonded to a water molecule. As a stereochemical consequence the transition state for dimerization in the $( \pm)$ fashion is favored relative to that for dimerization in the meso fashion. Another important aspect of this mechanistic feature is the fast, maybe even concerted, transfer of a hydrogenbonded proton from water to a carbonyl oxygen in the dimeric dianion, which causes the dimerization to be essentially irreversible.

The mechanism was supported by the observation of low Arrhenius activation energies $\left(<3 \mathrm{kcal} \mathrm{mol}^{-1}\right)$ indicating that the rate determining $\mathrm{C}-\mathrm{C}$ bond formation was indeed proceeded by an equilibrium step, i.e. the formation of the hydrogen-bonded radical anion-water complex. $^{23}$

The rate constants, $k_{\mathrm{dim}}$, for the dimerization were determined by DCV and found to vary between $4.1 \times 10^{2} \mathrm{M}^{-1} \mathrm{~s}^{-1}(\mathrm{R}=$ tert -butyl $)$ and $5.7 \times 10^{4} \mathrm{M}^{-1} \mathrm{~s}^{-1}$ ( $\mathrm{R}=4$-cyanophenyl) and the plot of $\log k_{\mathrm{dim}} \mathrm{vs.}$. the formal potential, $E^{\circ}$, for the substrate-radical anion redox couple was observed to be linear with a slope of $7.2 \mathrm{~V}^{-1}$ (Fig. 1A). Thus, the reactivity of the radical anions was found to decrease when the esters became less easy to reduce.

$$
2 \mathrm{Ph}-\mathrm{CH}=\mathrm{CH}-\mathrm{COOR} \stackrel{1 F}{\longrightarrow}
$$

Scheme 2.

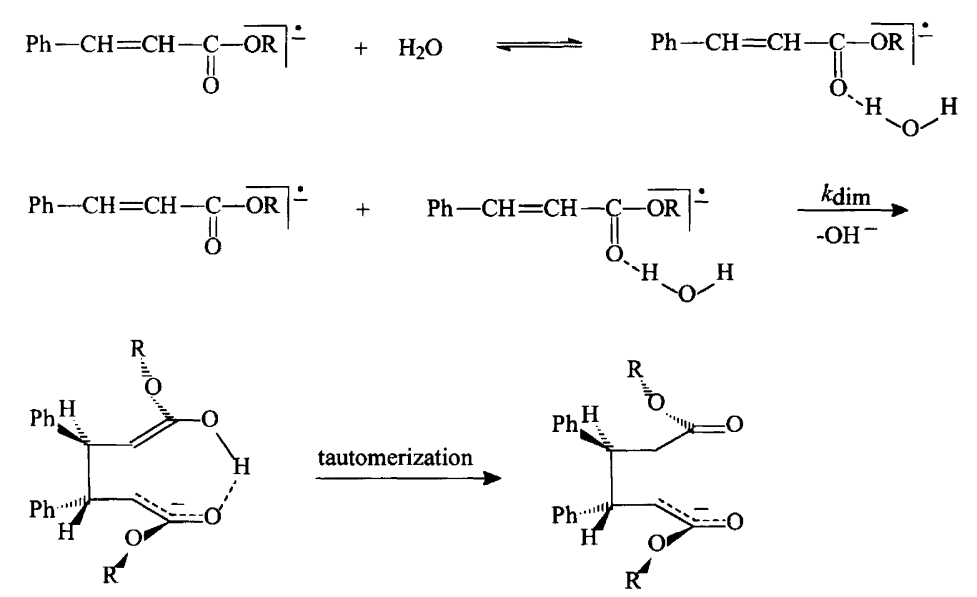

Scheme 3. 


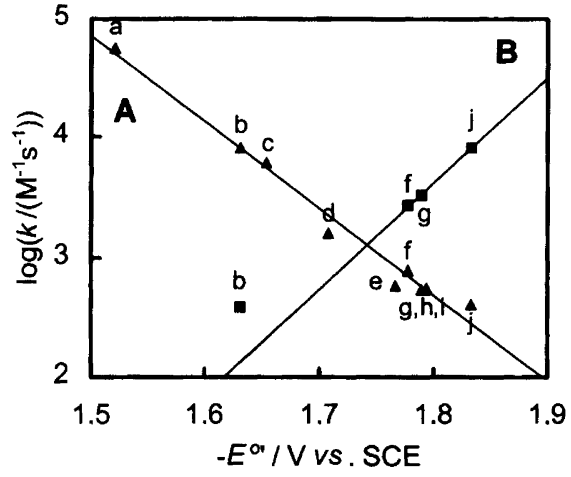

Fig. 1. Values of $\log k_{\mathrm{dim}}(\boldsymbol{\Delta})$ vs. $E^{\circ \prime}$ for the dimerization of cinnamic acid ester radical anions in DMF (A) and of log $k_{\text {prot }}$ (घ) vs. $E^{\circ \prime}$ for the protonation of cinnamic acid ester radical anions by phenol in DMF (B). The data point shown for phenyl cinnamate (b) was not included in the regression in (B), since $k_{\text {prot }}$ observed for this compound is clearly affected by a contribution from the dimerization reaction and, accordingly, is 'too large'. The esters included are p-cyanophenyl cinnamate (a), phenyl cinnamate (b), $p$-methoxyphenyl cinnamate (c), O-cinnamoyl- $\mathrm{N}$-tosylephedrine (d), O-cinnamoyl- $\mathrm{N}$ butylephedrine (e), methyl cinnamate (f), ethyl cinnamate (g), (-)-menthyl cinnamate (h), (-)-endo-bornyl cinnamate (i) and tert-butyl cinnamate (j). Experimental data from Refs. 19(a) and 19(b).

Protonation of radical anions derived from cinnamic acid esters. As a part of our continuing interest in protonation of radical anions, ${ }^{24}$ attempts were also made to study the kinetics for the electrochemical $2 \mathrm{~F}$ reduction of the cinnamates in DMF in the presence of phenol. The process leads to saturation of the $\mathrm{C}-\mathrm{C}$ double bond (Scheme 4$)^{25}$ and most likely involves protonation at C-2 as the rate-determining step (Scheme 5). ${ }^{19 b}$

$$
\mathrm{Ph}-\mathrm{CH}=\mathrm{CH}-\mathrm{COOR} \underset{\mathrm{PhOH}}{\stackrel{2 F}{\longrightarrow}} \mathrm{Ph}-\mathrm{CH}_{2}-\mathrm{CH}_{2}-\mathrm{COOR}
$$

Scheme 4.

$$
\begin{aligned}
& \mathrm{Ph}-\mathrm{CH}=\mathrm{CH}-\left.\mathrm{COOR}\right|^{-}+\mathrm{PhOH} \stackrel{k_{\text {prot }}}{\longrightarrow} \\
& \mathrm{Ph}-\dot{\mathrm{C}} \mathrm{H}-\mathrm{CH}_{2}-\mathrm{COOR}+\mathrm{PhO}^{-}
\end{aligned}
$$

\section{Scheme 5}

When the concentrations of the substrate and phenol were $2 \mathrm{mM}$ and $20-80 \mathrm{mM}$, respectively, the proton transfer reaction (Scheme 5) was found to compete effectively with dimerization (Scheme 3 ) for the alkyl cinnamates, whereas the kinetics for protonation of the radical anions derived from the aryl cinnamates were affected by the dimerization even at phenol concentrations in the $300-600 \mathrm{mM}$ range. For the simple alkyl cinnamates the rate constants, $k_{\text {prot }}$, obtained by DCV were found to be $2.7 \times 10^{3} \mathrm{M}^{-1} \mathrm{~s}^{-1}(\mathrm{R}=$ methyl $), 3.3 \times 10^{3} \mathrm{M}^{-1} \mathrm{~s}^{-1}(\mathrm{R}=$ ethyl $)$ and $8.2 \times 10^{3} \mathrm{M}^{-1} \mathrm{~s}^{-1}(\mathrm{R}=$ tert-butyl $)$. A preliminary plot of $\log k_{\text {prot }}$ vs. $E^{\circ \prime}$ is shown in Fig. $1 \mathrm{~B}$ and it is seen that the slope of the regression line has the opposite sign of that observed for the dimerization process. In other words, the reactivity of the radical anions in the reaction with an electrophile (phenol) was found to increase when the esters became less easy to reduce.

Reduction of cinnamic acid esters in methanol ( $\mathrm{MeOH})$. When the reduction of the cinnamates was carried out instead in $\mathrm{MeOH}$, the reaction took a different course. ${ }^{19 \mathrm{c}}$ The $n$-values obtained by constant current coulometry ${ }^{26}$ were between $1(\mathrm{R}=\mathrm{aryl})$ and $1.5(\mathrm{R}=\mathrm{alkyl})$ indicating in the latter case that $1 \mathrm{~F}$ and $2 \mathrm{~F}$ processes occurred simultaneously. Product studies for $\mathrm{R} \neq \mathrm{Me}$ were hampered by transesterification catalyzed by the base formed during the electrochemical reduction, but for $\mathrm{R}=\mathrm{Me}$ reduction on a preparative scale resulted in a mixture of the saturated ester, methyl 3-phenylpropionate, and the hydrodimer, dimethyl 3,4-diphenyladipate. The latter was formed with a ( \pm )-to-meso ratio close to one (Scheme 6 ).

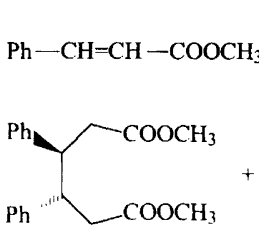

$( \pm)$
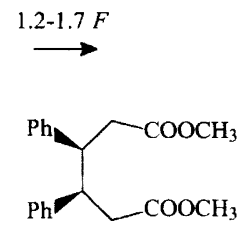

meso

$+\mathrm{Ph}-\mathrm{CH}_{2}-\mathrm{CH}_{2}-\mathrm{COOCH}_{3}$
Scheme 6 .

Results obtained by LSV at low sweep rates for $\mathrm{R}=$ alkyl were in agreement with a pseudo-first-order rate law, eqn. (3), compatible with a mechanism including rate-determining protonation: in this case at the carbonyl oxygen as shown in Scheme 7. The neutral radical formed in this way may either dimerize $(1 \mathrm{~F})$ or tautomerize to the radical corresponding to protonation at $\mathrm{C}-2$, which in turn is further reduced and protonated resulting, finally, in the saturated ester $(2 \mathrm{~F})$. In contrast, for $\mathrm{R}=$ aryl the LSV results were in agreement with a secondorder rate law, eqn. (4), indicating a mechanism with rate determining dimerization of two radical anions $(1 \mathrm{~F})$ as also illustrated in Scheme 7.

$$
\begin{array}{cc}
\mathrm{R}=\text { alkyl: } & -\mathrm{d}\left[\mathrm{Ph}-\mathrm{CH}=\mathrm{CH}-\mathrm{COOR}^{\circ}\right] / \mathrm{d} t \\
& =k_{\mathrm{prot}}\left[\mathrm{Ph}-\mathrm{CH}=\mathrm{CH}-\mathrm{COOR}^{\cdot-}\right] \\
\mathrm{R}=\text { aryl: } & -\mathrm{d}\left[\mathrm{Ph}-\mathrm{CH}=\mathrm{CH}-\mathrm{COOR}{ }^{-}\right] / \mathrm{d} t \\
& =2 k_{\mathrm{dim}}\left[\mathrm{Ph}-\mathrm{CH}=\mathrm{CH}-\mathrm{COOR}^{-}\right]^{2}
\end{array}
$$

The difference in the stereochemistry observed in aprotic solvents (DMF) containing small amounts of water and in hydroxylic solvents $(\mathrm{MeOH}$ for $\mathrm{R}=\mathrm{Me})$ reflects the different mechanisms in the two types of solvent. The relatively slow and stereoselective dimerization taking place in DMF involves two radical anions with a hydrogen-bonded water molecule serving as a template (Scheme 3), whereas in $\mathrm{MeOH}(\mathrm{R}=\mathrm{Me})$ two neutral radicals are involved in the dimerization 


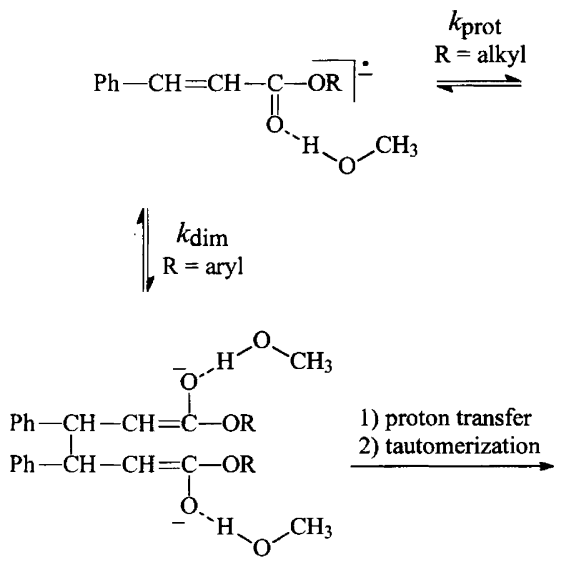

Scheme 7.

(Scheme 7), which for that reason is supposed to be fast and non-selective.

Approximate values of the rate constants, $k_{\text {prot }}$ and $k_{\mathrm{dim}}$, were extracted from the values of $E_{\mathrm{p}}-E^{\circ \prime}$ obtained during the LSV measurements. The values of $k_{\text {prot }}$ were in the range $3.5 \times 10^{3} \mathrm{M}^{-1} \mathrm{~s}^{-1} \quad(\mathrm{R}=$ ethyl $)$ to $2.0 \times 10^{2} \mathrm{M}^{-1} \mathrm{~s}^{-1} \quad[\mathrm{R}=\mathrm{Bu}(\mathrm{Me}) \mathrm{NCH}(\mathrm{Me}) \mathrm{CHPh}]$ and showed a tendency to increase when the esters became more difficult to reduce. In contrast, the values of $k_{\mathrm{dim}}$, which varied between $5.7 \times 10^{4} \mathrm{M}^{-1} \mathrm{~s}^{-1} \quad(\mathrm{R}=2,4,6-$ trimethylphenyl) and $2.0 \times 10^{6} \mathrm{M}^{-1} \mathrm{~s}^{-1}(\mathrm{R}=4$-cyanophenyl), showed a tendency to decrease when the esters became less easy to reduce. Thus, in spite of the mechanistic changes observed in passing from DMF to $\mathrm{MeOH}$ the relationship between reactivity of the radical anions and $E^{\circ \prime}$ was observed to be qualitatively the same in the two solvents.

Conclusions. The results from the studies of the cinnamates show that the reactivity of the radical anions in dimerization decreases, whereas the reactivity in reactions with electrophiles (proton donors) increases, when the substrates become less easy to reduce (cf. Fig. 1). This reactivity pattern obviously reflects the change in electronic properties of the radical anions with substitution and we have reported earlier ${ }^{27}$ that the DMF values of $\log k_{\text {dim }}$ correlate linearly with the unpaired electron density at the position of dimerization (C-3) and that the DMF values of $\log k_{\text {prot }}$ correlate linearly with the net atomic charge at the position of protonation (C-2). In the context of the present work we have carried out a more extensive series of AM1 calculations ${ }^{28}$ for the cinnamates (see Section V for computational and other details). Some of the results are shown graphically in Fig. 2 and it is seen that the unpaired electron density, $c_{\text {Somo }}^{2}$, at $\mathrm{C}-3$ and the net atomic charge, $q$, at C-2 do indeed vary linearly with the relative ease of reduction of the cinnamates, represented by $\Delta \Delta H_{\mathrm{f}}=\Delta H_{\mathrm{f}}^{\text {radical anion }}-\Delta H_{\mathrm{f}}^{\text {substrate }}$, in a fashion similar to that shown in Fig. 1 for the experimental data. The question now is to which extent this reactivity pattern is

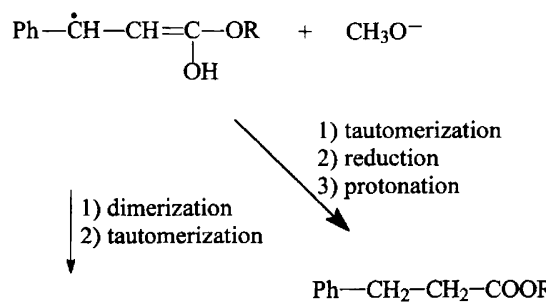

$\mathrm{Ph}-\mathrm{CH}-\mathrm{CH}_{2}-\mathrm{COOR}$
$\mathrm{Ph}-\mathrm{CH}-\mathrm{CH}_{2}-\mathrm{COOR}$

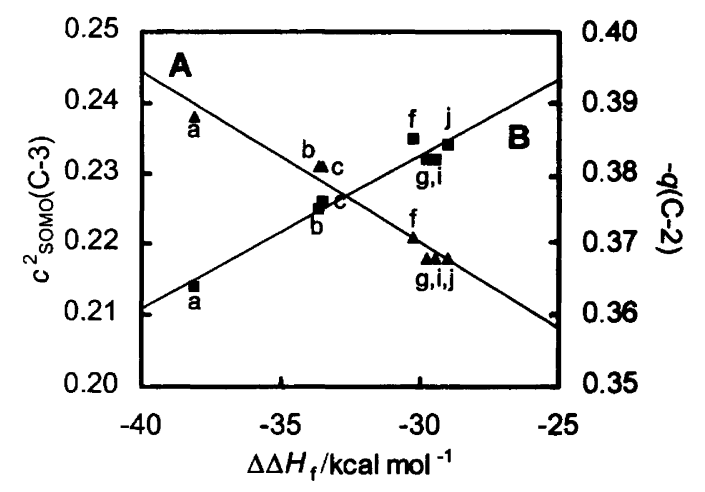

Fig. 2. Values of the unpaired electron density, $c_{\text {SoMo }}^{2}$, at $\mathrm{C}-3$ $(\mathrm{A}, \mathbf{\Delta})$ and the net atomic charge, $q$, at $\mathrm{C}-2(\mathrm{~B}, \mathbf{\mathrm { C }})$ vs. $\Delta \Delta H_{\mathrm{f}}$ ( $\left.=\Delta H_{f}^{\text {radical anion }}-\Delta H_{f}^{\text {substrate }}\right)$ for the radical anions of cinnamic acid esters. The abbreviations for the esters are the same as in Fig. 1. Data obtained by AM1 calculations as described in Section V.

general for radical anions. In order to answer this question we have carefully searched the literature for results obtained for other similar series of closely related radical anions and, in addition, examined the electronic properties of a large number of radical anions by AM1 calculations.

\section{Examp!es from the literature}

Somewhat to our surprise we were not able to locate other studies of radical anions in which both the product distribution and the kinetic and mechanistic details have been reported for an extended series of closely related radical anions differing only by the nature of a substituent in a remote position. In most cases data are only available for two or three substrates and usually only product data or kinetic data are reported. Below we present the results obtained in some typical studies.

EHD and hydrogenation of $\mathrm{N}$-ethyl maleimides. The reduction of $N$-ethyl maleimides in ethanolic aqueous buffers gives the corresponding hydrodimers and prod- 


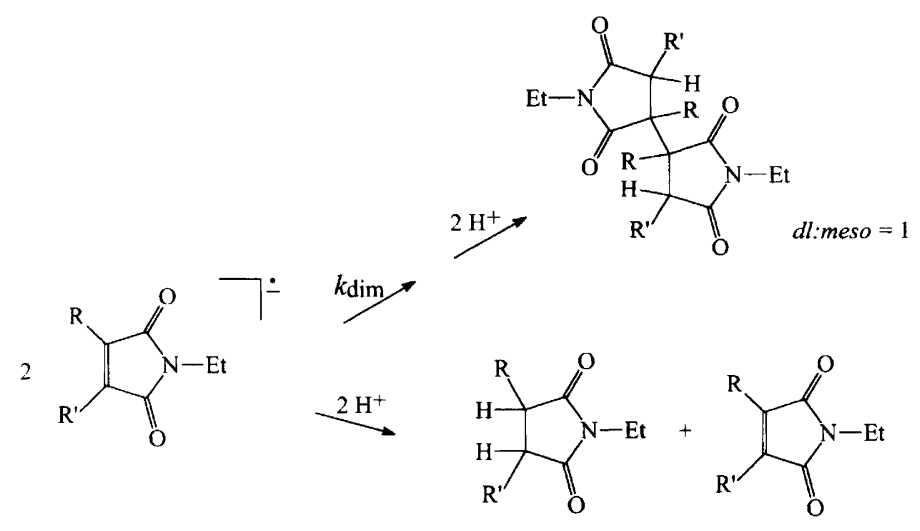

Scheme 8.

ucts resulting from saturation of the $\mathrm{C}-\mathrm{C}$ double bond ${ }^{29}$ (Scheme 8). A remarkable transition from the almost exclusive formation of the hydrodimer to the almost exclusive formation of the hydrogenation product is observed at $\mathrm{pH} 6$ in passing from the more easily reduced $\left(\mathrm{R}, \mathrm{R}^{\prime}=\mathrm{H}, \mathrm{H}\right)$ to the less easily reduced substrate $\left(\mathrm{R}, \mathrm{R}^{\prime}=\right.$ $\mathrm{CH}_{3}, \mathrm{CH}_{3}$ ) (Fig. 3). The observation that the hydrodimer derived from the unsymmetrically substituted derivative $\left(\mathrm{R}, \mathrm{R}^{\prime}=\mathrm{CH}_{3}, \mathrm{H}\right)$ had both methyl groups attached to the bridging carbons was taken as support for a dimerization mechanism including two radical anions and seems to indicate that steric effects are of only minor importance in determining the structure of the dimer. However, the lack of formation of a dimer from the fully substituted compound $\left(\mathrm{R}, \mathrm{R}^{\prime}=\mathrm{CH}_{3}, \mathrm{CH}_{3}\right)$ was attributed to steric hindrance.

EHD and hydrogenation of $\beta$-methylstyrenes. Allylbenzenes isomerize readily to the corresponding $\beta$ methylstyrenes in the presence of strong base, e.g., as formed during electrochemical reduction in aprotic solvents. This has been utilized in the electrochemical synthesis of $\beta$-methylstyrene hydrodimers (1,4-diaryl-2,3dimethylbutanes) in DMF using allylbenzenes as starting materials. ${ }^{30}$ In addition to the hydrodimers, the reaction

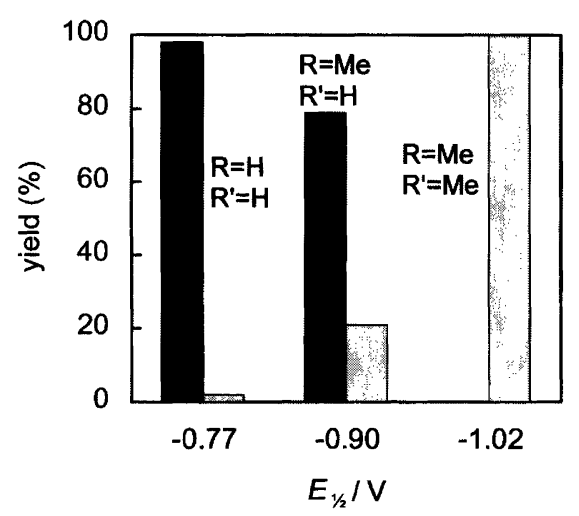

Fig. 3. Yields of hydrodimers (black bars) and hydrogenation products (light grey bars) from the cathodic reduction of $N$ ethyl maleimides in ethanolic buffers, $\mathrm{pH} 6$, vs. $E_{1 / 2}$ for reduction of the substrates. Experimental data from Ref. 29. mixture also contained the corresponding 1-arylpropanes resulting from saturation of the $\mathrm{C}-\mathrm{C}$ double bond (Scheme 9). The reduction potentials for the $\beta$-methylstyrene were not reported, but since the effect of substituents on $E^{\circ \prime}$ is well known for $m$ - and $p$-substituted benzenes $^{31}$ the relative ease of reduction of $\beta$-methylstyrenes carrying substituents in those two positions may be predicted with some confidence. The observed product distribution on passing from the more easily to the less easily reduced $\beta$-methylstyrenes is shown in Fig. 4 and it is seen that the more easily reduced substrates gave rise predominantly to the corresponding hydrodimers, whereas the less easily reduced substrates led mainly to the formation of the hydrogenation products.

Reversible dimerization of 9-substituted anthracene radical anions. The radical anions of anthracenes substituted in the 9-position with strongly electron-withdrawing substituents, e.g., $\mathrm{CN}, \mathrm{CHO}, \mathrm{COOCH}_{3}$ and $\mathrm{NO}_{2}$, undergo reversible dimerization through the 10-position in aprotic solvents such as DMF, acetonitrile and propylene carbonate (Scheme 10). ${ }^{32,33}$ The kinetics of the dimerization

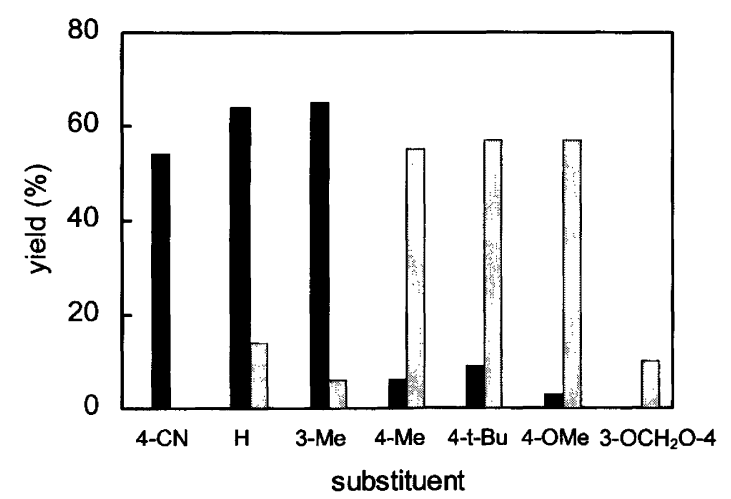

Fig. 4. Yields of hydrodimers (black bars) and hydrogenation products (light grey bars) from the cathodic reduction of ring substituted $\beta$-methyl styrenes in DMF. The data are given in the order of the expected $E^{\circ}$ with the most easily reduced substrate $(X=4-C N)$ to the left and the most difficultly reduced substrate $\left(X=3-\mathrm{OCH}_{2} \mathrm{O}-4\right)$ to the right. Experimental data from Ref. 30. 
<smiles>[X]C1CCCC(CC=C)C1</smiles><smiles></smiles><smiles>C/C=C\C1CCCCC1</smiles><smiles>C1CCCCC1</smiles><smiles>[X]c1ccccc1CC(C)C(C)Cc1ccccc1</smiles>

Scheme 9.

for the cyano, formyl and nitro derivatives have been studied by $\mathrm{DCV}^{32 \mathrm{a}}$ and double potential step chronoamperometry (DPSC) $)^{32 b, c}$ and the values of $k_{\text {dim }}$ were found to decrease in the order $\mathrm{NO}_{2}>\mathrm{CHO}>\mathrm{CN}$. The plot of $\log k_{\text {dim }}$ versus $\sigma^{-}$is linear as shown in Fig. 5, which indicates that faster dimerization is observed for the more easily reduced substrate. The enthalpies of activation were low or negative, e.g., $1.2 \mathrm{kcal} \mathrm{mol}^{-1}$ for $\mathrm{R}=$ $\mathrm{CN}$ and $-0.2 \mathrm{kcal} \mathrm{mol}^{-1}$ for $\mathrm{R}=\mathrm{NO}_{2}$ in DMF. ${ }^{32 \mathrm{~b}}$ This was taken as an indication that the dimerization reaction proceeds as a two-step process involving the formation of a $\pi$-complex (of unknown structure) prior to the formation of the bridging $\sigma$-bond. ${ }^{32}$

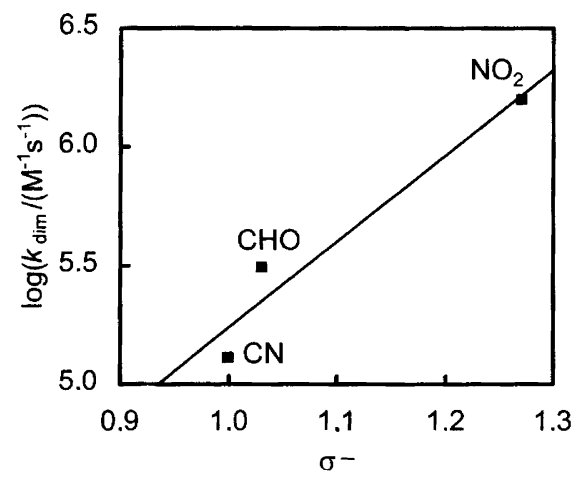

Fig. 5. Hammett plot, $\log k_{\text {dim }}$ vs. $\sigma^{-}$, for the dimerization of 9-substituted anthracene radical anions in DMF. Experimental data from Ref. 32(a).
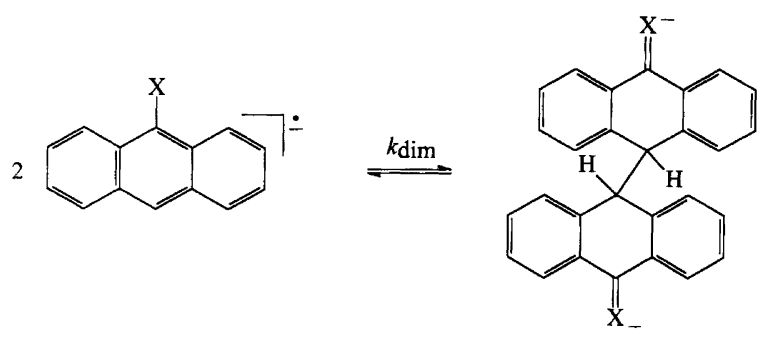

Scheme 10.
EHD and carboxylation of dialkyl fumarates. Dimethyl, diethyl and dibutyl fumarate all undergo EHD upon reduction in $\mathrm{DMF}^{34}$ as shown in Scheme 11. The results obtained by $\mathrm{CV}$ showed that the reaction following the initial electron transfer was relatively slow and thus it was possible to determine both $E_{\mathrm{p}}$ and $E_{\mathrm{p} / 2}-E_{\mathrm{p}}$ for the reversible (or quasi-reversible) reduction of the esters by $\mathrm{CV}$ at moderate sweep rates. The kinetics were studied by DPSC and chronocoulometry and the resulting values of $k_{\mathrm{dim}}$ were in the range $25-120 \mathrm{M}^{-1} \mathrm{~s}^{-1}$ and found to decrease in the order $\mathrm{CH}_{3}>\mathrm{CH}_{3} \mathrm{CH}_{2}>$ $\mathrm{CH}_{3} \mathrm{CH}_{2} \mathrm{CH}_{2} \mathrm{CH}_{2}$. The differences in rate observed were believed to reflect the increasing steric hindrance towards dimerization on passing from the smaller to the larger alkyl group. The results are shown graphically in Fig. 6A and it is seen that $\log k_{\text {dim }}$ is linearly dependent on $E^{\circ \prime}$ (estimated by us from the experimental data for $E_{\mathrm{p}}$ and $\left.E_{\mathrm{p}}-E_{\mathrm{p} / 2}\right)$.

The kinetics for the reaction between the same three radical anions and $\mathrm{CO}_{2}$ in DMF were studied separately. ${ }^{35}$ Results obtained by $\mathrm{CV}$, voltammetry at rotating ring-disk electrodes and EPR spectroscopy showed that the rate-determining step was indeed the bond formation between the radical anion and $\mathrm{CO}_{2}$. The pseudo-firstorder rate constants, $k_{\mathrm{CO}_{2}}$, obtained in solvent saturated with $\mathrm{CO}_{2}$ (approx. $0.2 \mathrm{M}$ ) were between 0.35 and $1.5 \mathrm{~s}^{-1}$ and were found to decrease in the same order as observed for the dimerization. The plot of $\log k_{\mathrm{CO}_{2}}$ vs. $E^{\circ \prime}$ is shown in Fig. 6B and it is seen that the plot is essentially linear.

Summary and conclusions. It appears that the experimental results reported in Section II for the cinnamate series are unique since this series is, to the best of our knowledge, the only one for which (1) the structural changes are limited to a substituent in a remote position, (2) the products have been identified, (3) the reaction mechanism is well characterized and (4) precise kinetic data are available.

For the 9-substituted anthracenes and the dialkyl fuma-

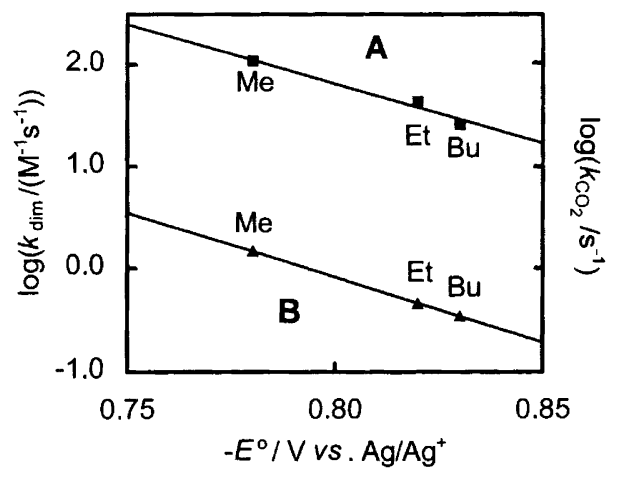

Fig. 6. Values of $\log k_{\text {dim }}$ for dimerization (A) and $\log k_{\mathrm{CO}_{2}}$ for the reaction with $\mathrm{CO}_{2}$ (B) for the radical anions of dialkyl fumarates in DMF vs. $E^{\circ \prime}$ for reduction of the substrates. The pseudo-first-order rate constants for (B) refer to a solution saturated with $\mathrm{CO}_{2}(0.2 \mathrm{M})$. Experimental data from Refs. 34 and 35 . 


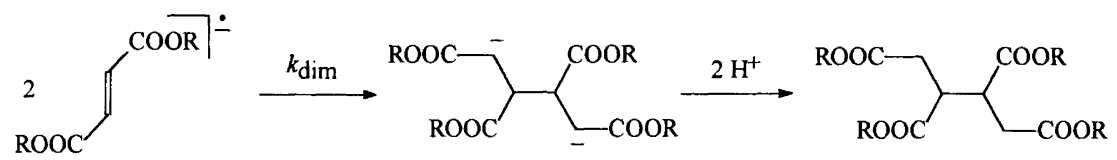<smiles>[R]OC(=O)C=CC(=O)OCC(=O)OCc1ccccc1</smiles>

Scheme 11.

rates, where kinetic data were reported, it was observed that $\log k_{\mathrm{dim}}$ decreased linearly with decreasing values of $E^{\circ \prime}$ and for the $N$-ethyl maleimides and the $\beta$-methylstyrenes, for which only product data were available, reduction was found to result predominantly in hydrodimers for the more easily reduced substrates and in products resulting from saturation of the $\mathrm{C}-\mathrm{C}$ double bond for the less easily reduced substrates. These data would seem to be in agreement with the observation made for the cinnamate radical anions that the reactivity of the radical anions in dimerization decreases and the reactivity in reactions with electrophiles (proton donors) increases when the substrates become less easy to reduce. This is illustrated in Fig. 7A for the general case. However, the product distributions observed for the $N$ ethyl maleimides and the $\beta$-methylstyrenes are compatible as well with the situation where $\log k_{\text {dim }}$ and $\log k_{\text {electrophile }}\left(=\log k_{\text {prot }}\right.$ ) both increase (Fig. 7B) or decrease (Fig. 7C) with decreasing values of $E^{\circ \prime}$, but with different slopes, and in one case, the reaction between the radical anions of the dialkyl fumarates and $\mathrm{CO}_{2}$, it was in fact observed that $\log k_{\mathrm{CO}_{2}}$ increased when the substrates became more easy to reduce. Thus, it seems impossible to draw general conclusions regarding the relationship between the ease of formation and the reactivity of the radical anions in dimerization and reactions with electrophiles, respectively, from the data presently available for radical anions.

The situation is slightly different for radical cations, first of all because more data are available. In most cases the reactivity pattern is analogous to that observed for the cinnamate radical anions, that is the reactivity of radical cations in dimerizations decreases and the reactivity in reactions with nucleophiles increases when the substrates become less easy to oxidize..$^{36-38}$ However, these trends for the radical cations are not universal either. For example, during the oxidation of triarylamines it was clearly observed that the reactivity of the corresponding radical cations in dimerization increases when the amines become less easily oxidized. ${ }^{39}$ On the other hand, we have not been able to locate exceptions in the general trend among the reactions between radical cations and nucleophiles.

The question that immediately comes into mind is whether the difference in reactivity observed for dimerizations reflects different mechanisms, and since the identi-

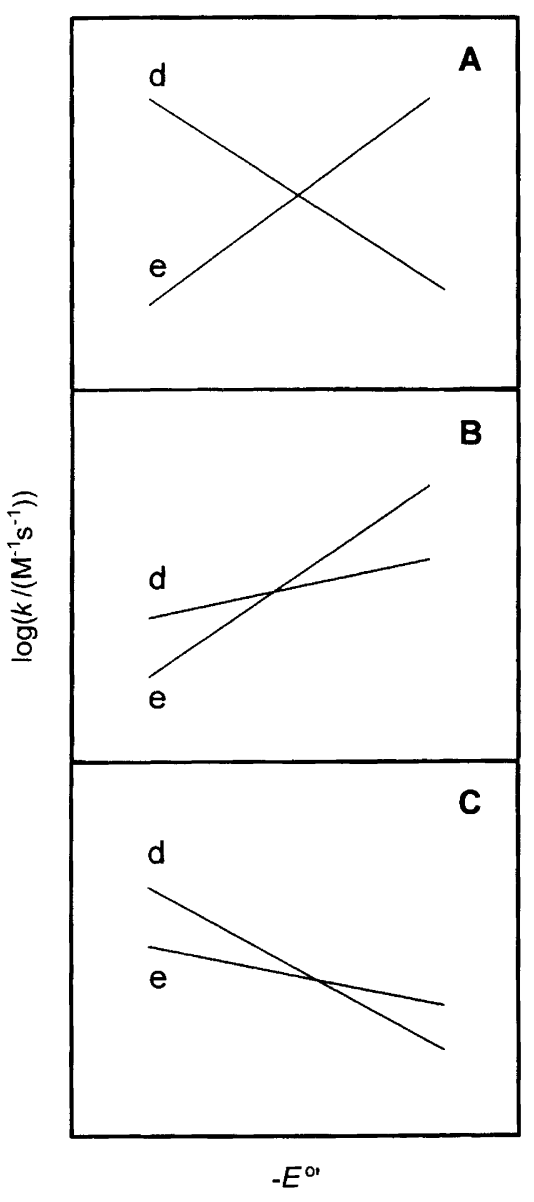

Fig. 7. Generalized plots of $\log k_{\mathrm{dim}}$ (d) and $\log k_{\text {electrophile }}(\mathrm{e})$ versus $E^{\circ \prime}$ for three different cases that all would lead predominantly to hydrodimers for substrates that are relatively easy to reduce and to products resulting from reaction between the radical anion and the electrophile for substrates that are relatively difficult to reduce.

fication of the species that actually react is a prerequisite for any discussion of radical ion reactivity, we will deal with this particular question in some detail below.

\section{Mechanisms for dimerization}

The mechanisms for radical ion reactions have been the subject of much discussion and this is true in particular for dimerizations. Although in this paper we focus on 
radical anions, the discussion to follow is relevant for the dimerization of radical cations as well and will for that reason be presented in more general terms.

The reductive, or oxidative, conversion of a substrate to a dimeric product is one of the most important reactions in synthetic organic electrochemistry. ${ }^{2,40,41}$ The substrates involved are typically alkenes or arenes activated towards electron transfer by the presence of an electron-withdrawing or electron-donating group. Results from numerous studies ${ }^{42-46}$ of the kinetics and mechanisms for dimerization seem to indicate that the $\mathrm{C}-\mathrm{C}$ bond forming step most often involves two radical ions, often referred to as the RR-mechanism. However, another mechanism, involving the coupling between a radical ion and a molecule of substrate and which by analogy is referred to as the RS-mechanism, has been proposed in a number of cases. ${ }^{42-46}$ (A more thorough discussion of the mechanism possibilities may be found elsewhere) ${ }^{47}$ The first steps in the two mechanisms are illustrated by eqns. (5)-(7), where $\mathrm{AX}$ is a substrate carrying an atom or group, $\mathrm{X}$, that may be eliminated as $\mathrm{X}^{-}$(for radical anions) or $\mathrm{X}^{+}$(for radical cations) after the formation of the doubly charged dimer, ${ }^{-1+} \mathrm{XA}-\mathrm{AX}^{-1+}$.

The RR-mechanism:

$2 \mathrm{AX}^{-1+} \underset{k_{-5}}{\stackrel{k_{5}}{\rightleftharpoons}-1+} \mathrm{XA}-\mathrm{AX}^{-1+} \quad\left(K_{5}=k_{5} / k_{-5}\right)$

The RS-mechanism:

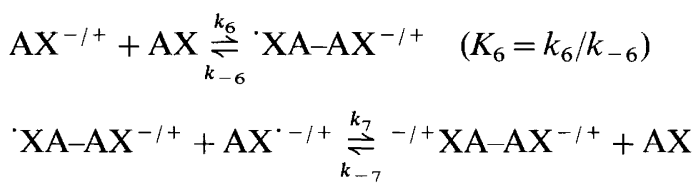

$\left(K_{7}=k_{7} / k_{-7}\right)$

In both cases ${ }^{-1+} \mathrm{XA}-\mathrm{AX}^{-1+}$ is converted into products in a subsequent step, eqn. (8a), that may involve an additional reagent, $Y$, eqn. $(8 b)$, or even the starting material, $\mathrm{AX}$, eqn. (8c).

$$
\begin{aligned}
& -1+\mathrm{XA}-\mathrm{AX}^{-1+} \underset{k_{-8 \mathrm{a}}}{\stackrel{k_{8 \mathrm{a}}}{\rightleftharpoons}} \text { products } \\
& { }^{-1+} \mathrm{XA}-\mathrm{AX}^{-1+}+\mathrm{Y} \underset{k_{-8 \mathrm{~b}}}{\stackrel{k_{8 \mathrm{~b}}}{\rightleftharpoons}} \text { products } \\
& -1+\mathrm{XA}-\mathrm{AX}^{-1+}+\mathrm{AX} \underset{k_{-8 \mathrm{c}}}{\stackrel{k_{8 \mathrm{c}}}{\rightleftharpoons}} \text { products }
\end{aligned}
$$

The nature of the reaction by which ${ }^{-1+} \mathrm{XA}-\mathrm{AX}^{-1+}$ is converted into the final product(s), eqns. (8a)-(8c), depends on both the structure of $\mathrm{AX}$ and the reaction conditions, including the nature of $\mathrm{Y}$, which may be a solvent component. For radical anions, the reaction typically involves double protonation of ${ }^{-} \mathrm{XA}-\mathrm{AX}^{-}$, resulting in the formation of the hydrodimer, ${ }^{41 \mathrm{~b}}$ HXA-AXH, or monoprotonation accompanied by cyclization of the Dieckmann type as illustrated in a previous paragraph for the reduction of the cinnamic acid esters. ${ }^{19 a, 20-22}$ In those cases the follow-up reaction requires the presence of a proton donor, $\mathrm{Y}$ or $\mathrm{AX}$. Other more rare cases, where $\mathrm{X}$ is a suitable leaving group, include the formation of A-A, which may be further reduced. ${ }^{48,49}$ The dimer dications, ${ }^{+} \mathrm{XA}-\mathrm{AX}^{+}$, resulting from the radical cation dimerization, may eliminate two protons ( $\mathrm{X}=\mathrm{H}$, dehydrodimerization) giving $\mathrm{A}-\mathrm{A} .{ }^{50} \mathrm{In}$ that case $\mathrm{Y}$ or $\mathrm{AX}$ is a proton acceptor. In other cases, the dimer dication may undergo cyclization, as for example observed for the dications derived from diarylethanes ${ }^{51}$ or 1,2-diarylethylenes. ${ }^{52}$ Finally, if $\mathrm{Y}$ is a good nucleophile, the further reaction of ${ }^{+} \mathrm{XA}-\mathrm{AX}^{+}$may instead lead to addition products, YXA-AXY, ${ }^{40}$ or if $\mathrm{AX}$ is good nucleophile, to the formation of oligomers or polymers.

Discussion of the mechanism in most of the earlier work $^{42-46}$ has been focussed on two so-called limiting cases, the RR-mechanism with irreversible dimerization, forward reaction (5), and the RS-mechanism with reversible coupling, reaction (6), followed by irreversible electron transfer, forward reaction (7). However, the arguments presented in favor of one or the other of the two mechanisms is, in our opinion, not always compelling and, in particular, the assumption of rate-determining dimerization in the RR-mechanism is in many cases an oversimplification of the kinetics. The analysis of the RR-mechanism has to include as the starting point also the rates of the dissociation of ${ }^{-1+} \mathrm{XA}-\mathrm{AX}^{-1+}$, back reaction (5), and its further conversion, reaction (8a), (8b) or (8c), and the neglect of these steps may lead to false conclusions regarding whether the $\mathrm{C}-\mathrm{C}$ bond forming step is of the RR- or the RS-type. A detailed discussion of this problem will appear elsewhere, ${ }^{53}$ but an example that illustrates this point is given in the Appendix. A second problem concerns the chemical nature of the further conversion of ${ }^{-1+} \mathrm{XA}-\mathrm{AX}^{-1+}$. As discussed above, this reaction often involves cases of protonation (for ${ }^{-} \mathrm{XA}-\mathrm{AX}^{-}$), or deprotonation (for ${ }^{+} \mathrm{XA}-\mathrm{AX}^{+}$), which in superdry aprotic solvents, for example containing suspended alumina, ${ }^{54}$ requires that either a solvent component, reaction (8b), or the starting material, reaction $(8 \mathrm{c})$, act as a donor or acceptor of protons. These reactions are not necessarily irreversible and, in addition, reaction $(8 \mathrm{c})$ consumes substrate. This introduces additional kinetic and mechanistic complications, which, if they are not taken properly into account, may also be the origin of a false mechanism assignment. ${ }^{53}$ In addition to these two problems, which are both of a purely chemical nature, the application of the LSV technique presents a third, technical problem. This concerns the determination of reaction orders from the variation of the peak potential with changes in the voltage sweep rate and in the substrate and reagent concentrations. Usually the analysis is based on three assumptions, (1) that the heterogeneous electron transfer process is reversible, (2) that the electrode process is under so-called kinetic control ${ }^{47}$ and (3) that the transport of material to and from the (planar) working 
electrode is governed by semi-infinite linear diffusion. In that case the relationship between the reaction orders and the peak potential variations is given by a set of simple equations (see the Appendix) that, in principle, should make the mechanism assignment easy. However, for second-order reactions (i.e., dimerizations) studied by LSV at working electrodes with diameters in the $0.2-2 \mathrm{~mm}$ range and substrate concentrations in the $0.5-5 \mathrm{mM}$ range, the assumption of purely kinetic conditions is often problematic. Under these conditions, typical for many LSV studies, the sweep rates required to maintain semi-infinite linear diffusion unaffected by convection are higher than the relatively low sweep rates required to fulfill the assumption of purely kinetic conditions. This introduces additional uncertainties into the mechanism assignment. ${ }^{53}$ In conclusion, we have found that the electroanalytical results reported for dimerizations in aprotic solvents, for the cases that were previously suggested to follow the RS-mechanism, with few exceptions may as easily be explained by the RR-mechanism when the problems just mentioned are taken into consideration in the data analysis. The exceptions all concern radical cations ${ }^{53}$ and for that reason we will assume in the section to follow that dimerizations involving radical anions as a rule proceed by the RR-mechanism.

It is important to emphasize, however, that we do not claim that the reaction between a radical ion and its substrate is rare in general, only that occurrence of the RS-mechanism in dimerization reactions under conditions where it may be characterized by electroanalytical techniques has, in our opinion, not been convincingly demonstrated in many cases. In fact, there is good evidence that the coupling between a radical ion and the neutral substrate may occur, e.g., when the radical cations of activated olefins are generated in very low (micromolar) concentrations with the substrate present in a large excess as happens during laser flash photolysis or pulse radiolysis studies. Owing to the low rate for the dimerization of two radical cations under such conditions, the rate of the RS-coupling, reaction (6), may well exceed that of the RR-dimerization, reaction (5). It is of interest to note that in many of those cases the overall reaction takes a different route, resulting in the radical cation catalyzed formation of cycloaddition products, i.e., cyclobutanes. ${ }^{7,12 e, 37,55}$ Analogous cycloadditions have also recently been reported for radical anions. ${ }^{56}$

\section{Results from semi-empirical molecular orbital calculations}

A common feature of the studies referred to in Sections II and III is that the structural changes in a series of compounds are limited to the variation of substituents, that owing to their nature or position, are expected to impose only small electronic perturbations of the original $\pi$-system. In fact, it is only for such systems that a linear relation between, e.g., $\log k$ and $E^{\circ \prime}$, would be expected.
In the light of the discussion in Section IV and the Appendix we will assume in the following that the dimerization of radical anions as a rule proceeds by the RR-mechanism and thus the relative values of $\log k_{\text {dim }}$ would be expected to a first approximation to be determined by the unpaired electron density, $c_{\text {Somo, }}^{2}$ at the carbon in the position of dimerization..$^{57,58}$ This again would lead to a linear relation between $\log k_{\mathrm{dim}}$ and $E^{\circ}$

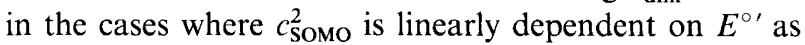
observed for the dimerization of the cinnamate radical anions (Figs. 1 and 2).

For the reactions between radical anions and electrophiles (proton donors) we consider only the large majority of the reactions that actually involve the radical anion in the bond-forming step, rather than the dianion formed by the disproportionation step of the radical anions. ${ }^{59,60}$ In the cases where the radical anion is the reactive species the relative values of $\log k_{\text {electrophile }}$ would be expected to be determined largely by the net atomic charge, $q$, at the carbon being attacked by the electrophile $^{57,61}$ (proton donor) and the difference in energy between the semi-occupied molecular orbital (SOMO) of the radical anion and the lowest unoccupied molecular orbital (LUMO) of the electrophile, $E_{\text {Sомо }}-$ $E_{\mathrm{LUMO}}^{\text {electrophile }} .{ }^{57}$ When the structural variations are limited to the radical anion, as in the reactions discussed in Sections II and III, $E_{\mathrm{LUMO}}^{\text {electrophile }}$ is a constant and it follows that a linear relation between $\log k_{\text {electrophile }}$ and $E^{\circ \prime}$ may be expected in the cases where $q$ and $E_{\text {Somo }}$ both correlate linearly with $E^{\circ \prime}$. The linear correlation between $\log k_{\text {prot }}$ and $E^{\circ \prime}$ observed for the protonation of the cinnamate radical anions is an example of such behavior (Figs. 1 and 2).

Thus, it would be expected that some understanding of the observed reactivity pattern for radical anions may be gained through molecular orbital calculations, e.g., at the AM1 level, ${ }^{28}$ of $c_{\text {Somo }}^{2}$ and $q$ at the relevant carbons and of $E_{\text {SOмо }}$. One problem inherent to this approach is that the results refer to an isolated species in the gas phase and it is indeed not a trivial task to include the effect of the solvent, ${ }^{62}$ and for the radical ions also the influence of counter ions, in the calculations of the electronic properties. However, since we are concerned here only with the trends in the reactivity we will assume

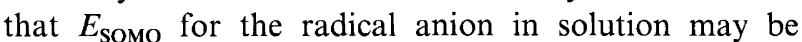
approximated by $E_{\text {LUMo }}$ for the neutral substrate in the gas phase reminiscent of the 'frozen orbital' approximation. ${ }^{63}$ Returning now to the previous paragraph this means that the requirement for observing a linear correlation between $\log k_{\text {electrophile }}$ and $E^{\circ \prime}$ is reduced to the existence of linear correlations between $q$ and $E^{\circ}$, since it has repeatedly been found ${ }^{64-66}$ that $E_{\text {LUMO }}$ (or the vertical gas phase electron affinity) and $E^{\circ \prime}$ are indeed linearly related for series of related substrates.

In order to gain some general insight into the effect of substituents on the electronic properties of radical anions, AM1 calculations were carried out not only for the compounds for which experimental results are presented 
in Sections II and III, but also for seven series of model compounds, 1-7. The structures of these, which in a few cases overlap with the compounds for which experimental data were available, are shown in Scheme 12. The identity of the substituents ( $R$ ) are given in the captions to the figures referred to below. The values of $E^{\circ \prime}$ for the model compounds were approximated by the adiabatic gas phase electron affinities, $\Delta \Delta H_{\mathrm{f}}=\Delta H_{\mathrm{f}}^{\text {radical anion }}$ $\Delta H_{\mathrm{f}}^{\text {substrate }},{ }^{67-69}$ rather than by $E_{\mathrm{Lumo}}$. However, the results obtained for the seven series of model compounds showed that the plots of $E_{\text {Lumo }}$ vs. $\Delta \Delta H_{\mathrm{f}}$ were essentially linear with slopes of the regression lines between 0.92 and 1.03 .

The computational procedure involved the following steps. (1) The structure of the neutral substrate was first optimized by a molecular mechanics calculation (PCModel, v. 6.00). (2) This structure was then used as the input for an AM1-RHF (MOPAC, v. 6.0 for PCs) calculation to determine $\Delta H_{\mathrm{f}}^{\text {substrate }}$. (3) The structure optimized by the molecular mechanics calculation was also used as input for an AM1-UHF calculation of the unpaired electron density, $c_{\text {Somo, }}^{2}$ and the net atomic charge, $q$, at the relevant carbon(s) in the radical anion. (4) Finally, $\Delta H_{\mathrm{f}}^{\text {radical anion }}$ was calculated by an AM1RHF calculation, usually using the AM1-UHF optimized structure as input. All calculations were performed using the PRECISE option and without symmetry restrictions. Nitro substituents were avoided, except for radical anions for which kinetic data are available, owing to the large errors in $\Delta H_{\mathrm{f}}$ that may result from AM1 calculations for, e.g., nitroarenes. ${ }^{70}$<smiles>[R]/C=C\[H]</smiles>

1

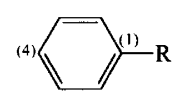

3<smiles>[R]c1c2ccccc2cc2ccccc12</smiles>

5<smiles>[R]OC(=O)C=Cc1ccccc1</smiles>

Scheme 12.

\section{The model systems}

Ethylene and monosubstituted ethylenes. The results obtained by AM1 (RHF or UHF) calculations for the unsubstituted ethylene radical anion predict a planar configuration with the unpaired electron density symmetrically distributed between the two carbons corresponding to a value of $c_{\text {Sомо }}^{2}$ equal to 0.5 for each carbon. The net atomic charge, $q$, at each carbon is -0.549 and $\Delta \Delta H_{\mathrm{f}}$ is $25.76 \mathrm{kcal} \mathrm{mol}^{-1}$.

The effects of monosubstitution (1) are shown in Figs. 8 and 9. It is seen that $c_{\text {somo }}^{2}$ at both C-1 (Fig. 8A) and C-2 (Fig. 8B) for $\mathrm{R}$ equal to alkyl or substituted alkyl ( $\boldsymbol{\square}$ ) in all cases is only slightly smaller than 0.5 . At the carbon to which $\mathrm{R}$ is attached, $\mathrm{C}-1$, the values are between 0.48 and 0.5 with a weak tendency to decrease with decreasing values of $\Delta \Delta H_{\mathrm{f}}$. At $\mathrm{C}-2$ the values tend to increase slightly with decreasing values of $\Delta \Delta H_{\mathrm{f}}$. The slope of the regression line defined by the data for C-2 is $-8.4 \times 10^{-4} \mathrm{~mol} \mathrm{kcal}^{-1}$. These trends are accompanied by opposing trends for the net atomic charge, $-q$, the values of which are found to increase at $\mathrm{C}-1$ (Fig. 9A)

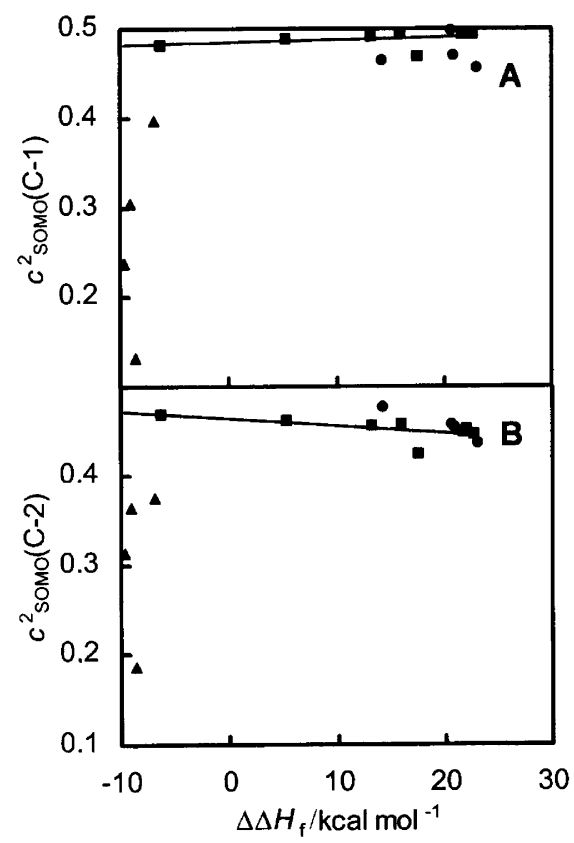

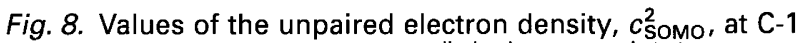
(A) and C-2 (B) vs. $\Delta \Delta H_{f}\left(=\Delta H_{f}^{\text {radical anion }}-\Delta H_{f}^{\text {substrate }}\right)$ for the radical anions of monosubstituted ethylenes (1). The data points shown as filled squares $(\square)$ are for alkyl or substituted alkyl groups and include (from left to right) $\mathrm{CF}_{3}, \mathrm{CHF}_{2}, \mathrm{CH}_{2} \mathrm{~F}$, $\mathrm{CH}_{2} \mathrm{NH}_{2}, \mathrm{CH}_{2} \mathrm{OCH}_{3}, \mathrm{CH}_{2} \mathrm{CH}_{2} \mathrm{CH}_{2} \mathrm{CH}_{3}, \mathrm{CH}_{2} \mathrm{CH}_{3}$ and $\mathrm{CH}_{3}$. The data points shown as filled circles (O) are for substituents having a heteroatom carrying a lone-pair directly attached to the ethylene $\pi$-system and include (from left to right) $F, \mathrm{NH}_{2}$, $\mathrm{OH}$ and $\mathrm{OCH}_{3}$. The data points shown as filled triangles $(\boldsymbol{\Delta})$ are for $\pi$-type substituents and include (from left to right) $\mathrm{COCH}_{3}, \mathrm{COOCH}_{3}, \mathrm{C}_{6} \mathrm{H}_{5}$ and $\mathrm{CN}$. The slopes of the regression lines determined by the points for the alkyl or substituted alkyl groups (D) are $3.0 \times 10^{-4} \mathrm{~mol} \mathrm{kcal}^{-1}$ (A) and $-8.4 \times 10^{-4} \mathrm{~mol} \mathrm{kcal}^{-1}$ (B). Data obtained by AM1 calculations as described in the text. 


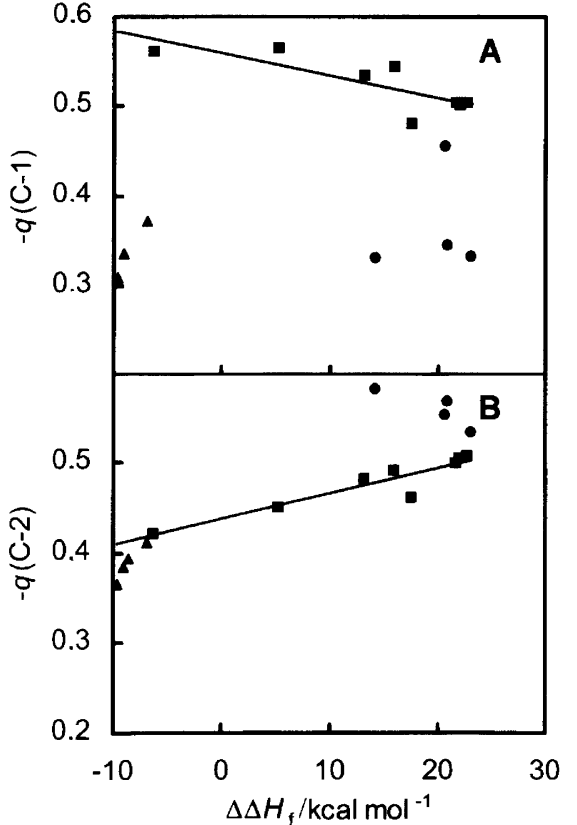

Fig. 9. Values of the net atomic charge, $q$, at $\mathrm{C}-1$ (A) and C-2 (B) vs. $\Delta \Delta H_{f} \quad\left(=\Delta H_{f}^{\text {radical anion }}-\Delta H_{f}^{\text {substrate }}\right)$ for the radical anions of monosubstituted ethylenes (1). The data points refer to the same substituents and calculations as in Fig. 8 . The slopes of the regression lines determined by the points for the alkyl or substituted alkyl groups ( $\mathbf{D})$ are $-2.5 \times 10^{-3}$ $\mathrm{mol} \mathrm{kcal}^{-1}(\mathrm{~A})$ and $2.9 \times 10^{-3} \mathrm{~mol} \mathrm{kcal}^{-1}(\mathrm{~B})$.

and to decrease at C-2 (Fig. 9B) with decreasing values of $\Delta \Delta H_{\mathrm{f}}$. Also in this case the effect is larger at $\mathrm{C}-2$, for which the slope of the regression line is equal to $2.9 \times 10^{-3} \mathrm{~mol} \mathrm{kcal}^{-1}$.

A similar, slightly larger effect on $c_{\text {Sомо }}^{2}$ is observed when $\mathrm{R}$ has a heteroatom carrying a lone-pair directly attached to the ethylene $\pi$-system ( $)$, but the effect of these substitutents on $\Delta \Delta H_{\mathrm{f}}$ is too small to allow for conclusions regarding a possible relationship between $c_{\text {SOMo }}^{2}$ and $\Delta \Delta H_{\mathrm{f}}$. In fact, it may be argued that in a radical anion, the effect of introducing a substituent having a lone pair at the atom attached to the ethylene carbon is mainly of an electrostatic nature and therefore that these radical anions might as well have been included in the series of ethylenes carrying alkyl or alkyl-like substituents. However, the effect on the net atomic charge of a substituent having a lone pair at the atom attached to the ethylene carbon is clearly different from that found for the alkyl or alkyl-like substituents as seen in Figs. $9 \mathrm{~A}$ and $9 \mathrm{~B}$. At $\mathrm{C}-1$ the values of $-q$ are significantly lower than those for the alkyl substitutents (Fig. 9A), whereas the values at C-2 are significantly higher (Fig. 9B) and with a tendency to increase with decreasing values of $\Delta \Delta H_{\mathrm{f}}$.

A much larger effect is observed when $R$ is a $\pi$-type substituent $(\mathbf{\Delta})$. From Figs. $8 \mathrm{~A}$ and $8 \mathrm{~B}$ it is seen that the values of $c_{\text {SOMo }}^{2}$ are now significantly smaller than 0.5 at both $\mathrm{C}-1$ and $\mathrm{C}-2$. This obviously is caused by the effective delocalization of the unpaired electron density into these substituents, the extent depending on the nature of the substituent. Thus, the substitution of a hydrogen atom in ethylene with a $\pi$-type substituent exceeds by far that of a small perturbation and accordingly there is no relationship between $c_{\text {SOMo }}^{2}$ and $\Delta \Delta H_{\mathrm{f}}$. A similar effect is observed for the values of $-q$, although the effect is much smaller at C-2 (Fig. 9B) than at C-1 (Fig. 9A).

Symmetrical 1,2-disubstituted ethylenes. The effects of introducing two identical substituents in the 1- and 2positions (2) are shown in Figs. 10 and 11. It is seen that $c_{\text {Somo (Fig. 10) increases slightly with decreasing }}^{2}$

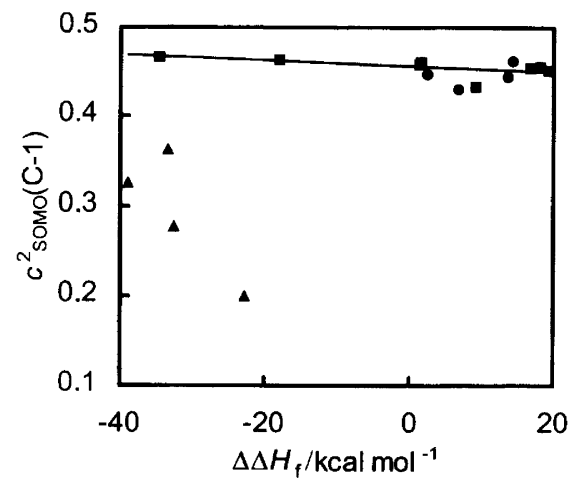

Fig. 10. Values of the unpaired electron density, $c_{\text {somo, at }}^{2}$ C-1 $(=\mathrm{C}-2)$ vs. $\Delta \Delta H_{f}\left(=\Delta H_{f}^{\text {radical anion }}-\Delta H_{f}^{\text {substrate }}\right)$ for the radical anions of 1,2-disubstituted ethylenes (2). The data points shown as filled squares ( $\boldsymbol{\square}$ ) are for alkyl or substituted alkyl groups and include (from left to right) $\mathrm{CF}_{3}, \mathrm{CHF}_{2}, \mathrm{CH}_{2} \mathrm{~F}$, $\mathrm{CH}_{2} \mathrm{NH}_{2}, \mathrm{CH}_{2} \mathrm{OCH}_{3}, \mathrm{CH}_{2} \mathrm{CH}_{2} \mathrm{CH}_{2} \mathrm{CH}_{3}, \mathrm{CH}_{2} \mathrm{CH}_{3}$ and $\mathrm{CH}_{3}$. The data points shown as filled circles (O) are for substituents having a heteroatom carrying a lone-pair directly attached to the ethylene $\pi$-system and include (from left to right) $F$, $\mathrm{OCH}_{3}, \mathrm{OH}$, and $\mathrm{NH}_{2}$. The data points shown as filled triangles ( $\Delta$ ) are for $\pi$-type substituents and include (from left to right) $\mathrm{COOCH}_{3}, \mathrm{CN}, \mathrm{COCH}_{3}$ and $\mathrm{C}_{6} \mathrm{H}_{5}$. The slope of the regression line determined by the points for the alkyl or substituted alkyl groups ( $\boldsymbol{\square}$ ) is $-3.3 \times 10^{-4} \mathrm{~mol} \mathrm{kcal}^{-1}$. Data obtained by AM1 calculations as described in the text.

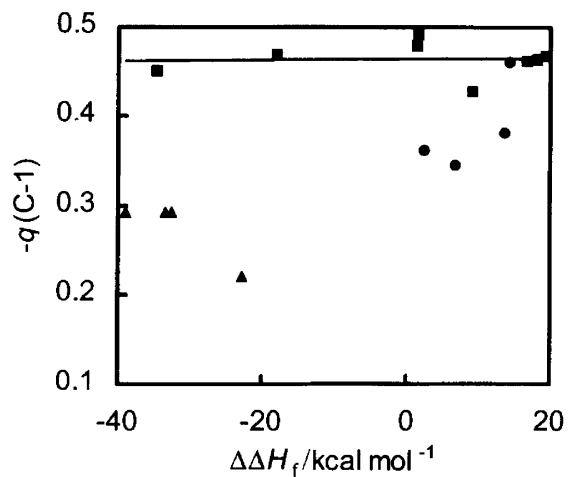

Fig. 11. Values of the net atomic charge, $q$, at $\mathrm{C}-1(=\mathrm{C}-2)$ vs. $\Delta \Delta H_{f}\left(=\Delta H_{f}^{\text {radical anion }}-\Delta H_{f}^{\text {substrate }}\right)$ for the radical anions of 1,2-disubstituted ethylenes (2). The data points refer to the same substituents and calculations as in Fig. 10. The slope of the regression line determined by the points for the alkyl or substituted alkyl groups ( $)$ is $2.2 \times 10^{-4} \mathrm{~mol} \mathrm{kcal}^{-1}$. 
values of $\Delta \Delta H_{\mathrm{f}}$ in a fashion similar to that observed for $\mathrm{C}-2$ in the monosubstituted ethylene radical anions, $\mathbf{1}$, when $\mathrm{R}$ is restricted to be of the alkyl or substituted alkyl type ( $\boldsymbol{\square})$. The slope of the regression line in this case, $-3.3 \times 10^{-4} \mathrm{~mol} \mathrm{kcal}^{-1}$, is (numerically) slightly smaller than the value, $-8.4 \times 10^{-4} \mathrm{~mol} \mathrm{kcal}^{-1}$, observed for 1. This smaller effect is seen even more clearly for $-q$ (Fig. 11), which varies only little with changing values of $\Delta \Delta H_{\mathrm{f}}$. Thus, for both $c_{\text {somo }}^{2}$ and $-q$ the effect of having two identical substituents situated symmetrically around the $\mathrm{C}-\mathrm{C}$ double bond is slightly smaller than that observed for the unsymmetrical monosubstituted ethylene radical anions. The same tendency is also observed for the substituents having a lone pair at the atom attached to the ethylene carbon $(\bullet)$ and the $\pi$-type substituents ( $\mathbf{A})$.

Monosubstituted benzenes. The effect of substitution on the stability and charge distribution for a series of monosubstituted benzenes and their radical anions has earlier been discussed in detail in two pioneering studies based on $a b$ initio STO-3G calculations. ${ }^{71}$ The results from these studies indicate that $\mathrm{C}-4$ is the thermodynamically preferred site of protonation of the radical anions for alkyl and $\pi$-type (acceptor) substituents and that there is generally a close parallel between the thermodynamically and the kinetically preferred protonation site.

The values of $c_{\text {Somo }}^{2}$ and $-q$ for a series of monosubstituted benzenes (3) obtained by the AM1 method are summarized in Figs. 12 and 13, respectively. With only one exception $(\mathrm{R}=$ vinyl $)$ the highest values of $c_{\text {Somo }}^{2}$ are found at $\mathrm{C}-1$ (ipso) and $\mathrm{C}-4$ (para) as long as $\mathrm{R}$ belongs to the classes of alkyl-type or $\pi$-type substituents although significant values of $c_{\text {Somo }}^{2}$ are also found in other ring positions.

It is seen at Fig. 12 that the values of $c_{\text {Somo }}^{2}$ increase at the carbon to which the substituent is attached, C-1, and decrease at the hypothetical position for dimerization, C-4, with decreasing values of $\Delta \Delta H_{\mathrm{f}}$, again when $\mathrm{R}$ is being restricted to alkyl or substituted alkyl ( $\boldsymbol{\square})$. These tendencies are the opposite of what was observed for the series of substituted ethylenes, 1. The slope of the regression line defined by the values of $c_{\text {SOMo }}^{2}$ at $\mathrm{C}-4$ is $1.5 \times 10^{-3} \mathrm{~mol} \mathrm{kcal}^{-1}$ which (numerically) is slightly larger than the value, $-8.4 \times 10^{-4} \mathrm{~mol} \mathrm{kcal}^{-1}$, at the equivalent position, $\mathrm{C}-2$, in 1 . The trends observed for $c_{\text {Somo }}^{2}$ are paralleled by similar trends for $-q$ as seen in Fig. 13. This is also at variance with the results obtained for the ethylenes. It is of interest to note that the values of $c_{\text {SOMo }}^{2}$ at $\mathrm{C}-1$ and $\mathrm{C}-4$ are of similar magnitudes for the compounds having the highest values of $\Delta \Delta H_{\mathrm{f}}$, but, owing to the opposite trends in $c_{\text {SOMo }}^{2}$ with decreasing values of $\Delta \Delta H_{\mathrm{f}}$, we find that $c_{\text {Somo }}^{2}$ at $\mathrm{C}-1$ is almost $50 \%$ larger than $c_{\text {Somo }}^{2}$ at $\mathrm{C}-4$ for the compounds with the lowest values of $\Delta \Delta H_{\mathrm{f}}$, that is for the compounds expected to be most easily reduced.

When $\mathrm{R}$ consists of an atom carrying a lone pair

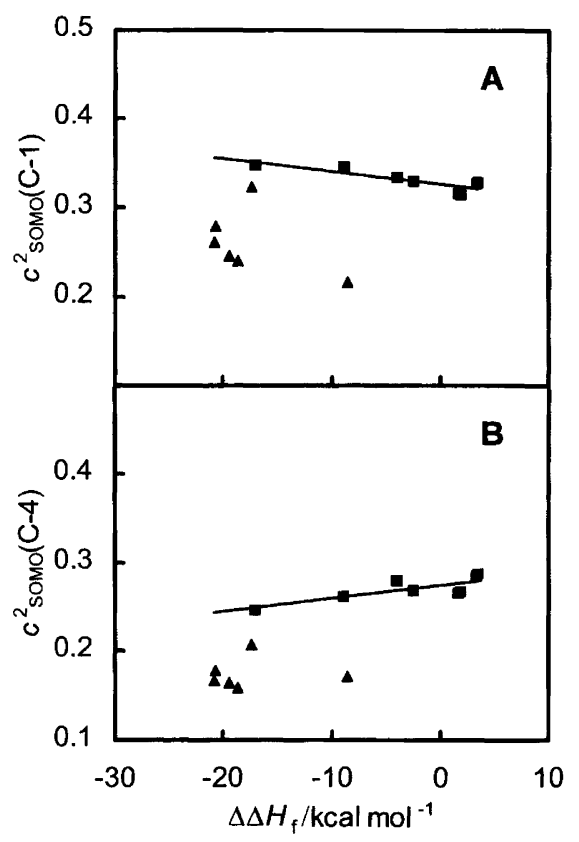

Fig. 12. Values of the unpaired electron density, $c_{\text {Somo, }}^{2}$ at C- 1 (A) and C-4 (B) vs. $\Delta \Delta H_{f}\left(=\Delta H_{f}^{\text {radical anion }}-\Delta H_{f}^{\text {substrate }}\right)$ for the radical anions of monosubstituted benzenes (3). The data points shown as filled squares $(\boldsymbol{D})$ are for alkyl or substituted alkyl groups and include (from left to right) $\mathrm{CF}_{3}, \mathrm{CHF}_{2}$, $\mathrm{CH}_{2} \mathrm{NH}_{2}, \mathrm{CH}_{2} \mathrm{~F}, \mathrm{CH}_{2} \mathrm{OCH}_{3}, \mathrm{CH}_{2} \mathrm{OH}, \mathrm{CH}_{2} \mathrm{CH}_{3}$ and $\mathrm{CH}_{3}$. The data points shown as filled triangles $(\mathbf{\Delta})$ are for $\pi$-type substituents and include (from left to right) $\mathrm{COOCH}_{3}, \mathrm{COOH}$, $\mathrm{CHO}, \mathrm{COCH}_{3}, \mathrm{CN}$ and $\mathrm{CH}=\mathrm{CH}_{2}$. The slopes of the regression lines determined by the points for the alkyl or substituted alkyl groups (D) are $-1.4 \times 10^{-3} \mathrm{~mol} \mathrm{kcal}^{-1}$ (A) and $1.5 \times 10^{-3} \mathrm{~mol} \mathrm{kcal}^{-1}$ (B). Data obtained by AM1 calculations as described in the text.

attached to the benzene ring we see no clear positional preference for the maximum $c_{\text {SOMo }}^{2}$ value (not included in Figs. 12 and 13).

The effect of introducing substituents of the $\pi$-type (A) into the benzene ring is very similar to that observed for the ethylenes illustrating that in this case the effects are also larger than that expected for a small perturbation.

1-Substituted 2,6-di-tert-butylbenzenes. A common feature of the model compounds derived from ethylene and benzene is that the introduction of a $\pi$-type substituent leads to a new, larger $\pi$-system than that for the parent compound and hence we observe no clear relationships between $c_{\text {SOMo }}^{2}$ and $q$, respectively, and $\Delta \Delta H_{\mathrm{f}}$. One way to avoid the effect of conjugation would of course be to carry out a series of calculations for the conformations, e.g., of the monosubstituted benzenes, in which the dihedral angle between the parent and substituent $\pi$-systems was fixed at $90^{\circ}$. However, the results would be of only little relevance to practical work and we preferred instead to carry out calculations for a series of 1-substituted 2,6-di-tert-butylbenzenes (4) in which the conjugation between the two $\pi$-systems is strongly minim- 


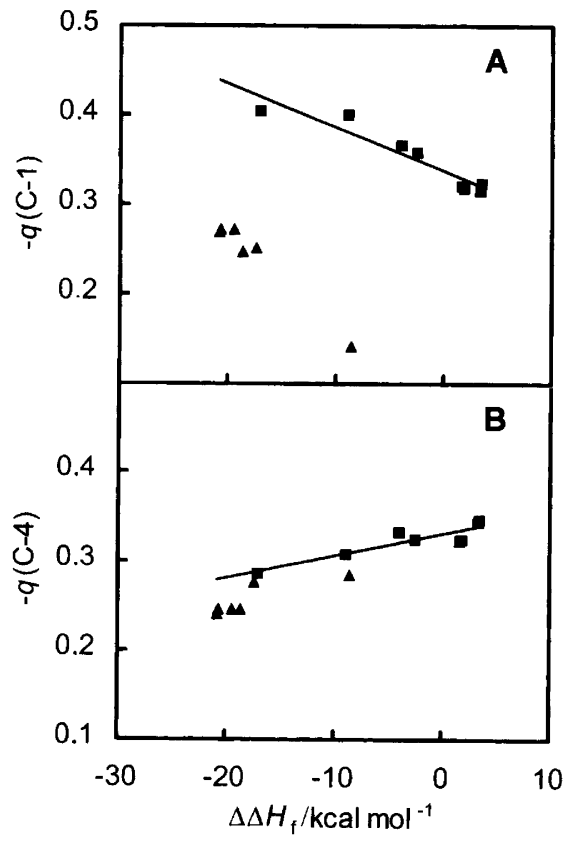

Fig. 13. Values of the net atomic charge, $q$, at $\mathrm{C}-1$ (A) and C-4 (B) vs. $\Delta \Delta H_{f}\left(=\Delta H_{f}^{\text {radical anion }}-\Delta H_{f}^{\text {substrate }}\right)$ for the radical anions of monosubstituted benzenes (3). The data points refer to the same substituents and calculations as in Fig. 12. The slopes of the regression lines determined by the points for the alkyl or substituted alkyl groups $(D)$ are $-4.9 \times 10^{-3}$ $\mathrm{mol} \mathrm{kcal}^{-1}(\mathrm{~A})$ and $2.5 \times 10^{-3} \mathrm{~mol} \mathrm{kcal}^{-1}$ (B).

ized owing to the steric hindrance of coplanarity exerted by the tert-butyl groups. The results are shown in Figs. 14 and 15 .

The effect of the two tert-butyl groups is seen most clearly by comparison of the figures for systems with and without tert-butyl groups, one-by-one. Beginning with C-1 (Figs. 12A and 14A), we see almost no effect of the tert-butyl groups as long as $\mathrm{R}$ belongs to the class of alkyl and alkyl-like substituents ( $\mathbf{\square})$, as also expected. The values of $c_{\text {SOMo }}^{2}$ are in all cases not far from 0.35 although the dependence on $\Delta \Delta H_{\mathrm{f}}$ is slightly smaller in the presence of the tert-butyl groups. A significant effect of the tert-butyl groups is seen for the $\pi$-type substituents $(\Delta)$. Three of the substituents $\left(\mathrm{CHO}, \mathrm{COOCH}_{3}\right.$ and $\mathrm{CN}$ ) now result in values of $c_{\text {somo }}^{2}$ that are close to those predicted by the regression line defined by the alkyl and alkyl-like substituents illustrating that the interaction between these three substituents and the benzene $\pi$-system in the presence of the 2,6-di-tert-butyl groups is of a nature similar to that of the alkyl-type substituents. In the radical anion of the 2,6-di-tert-butyl substituted styrene $(R=$ vinyl) the substituent still carries a significant amount of the unpaired electron density and in the radical anion of 2,6-di-tert-butylacetophenone $(\mathrm{R}=$ $\mathrm{COCH}_{3}$, not shown in Figs. 14 and 15) the calculations predict that the unpaired electron density is carried almost exclusively by the acetyl substituent resulting in only very small values of $c_{\text {Somo }}^{2}$ at the benzene carbons.

A similar effect is seen for C-4 (Figs. 12B and 14B),

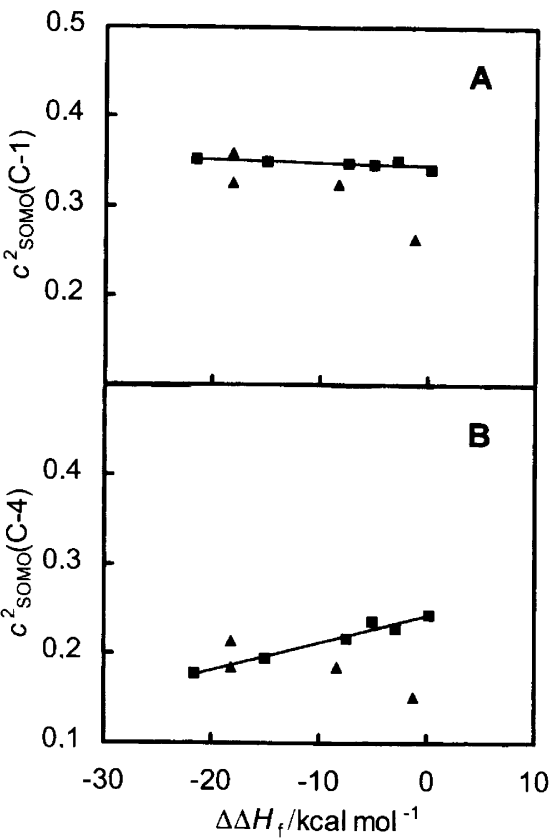

Fig. 14. Values of the unpaired electron density, $c_{\text {somo, at }}^{2}$ C- $1(A)$ and $C-4(B)$ vs. $\Delta \Delta H_{f}\left(=\Delta H_{f}^{\text {radical anion }}-\Delta H_{f}^{\text {substrate }}\right)$ for the radical anions of 1-substituted 2,6-di-tert-butylbenzenes (4). The data points shown as filled squares ( $\square$ ) are for alkyl or substituted alkyl groups and include (from left to right) $\mathrm{CF}_{3}, \mathrm{CHF}_{2}, \mathrm{CH}_{2} \mathrm{~F}, \mathrm{CH}_{2} \mathrm{NH}_{2}, \mathrm{CH}_{2} \mathrm{OH}$ and $\mathrm{CH}_{3}$. The data points shown as filled triangles $(\boldsymbol{\Delta})$ are for $\pi$-type substituents and include (from left to right) $\mathrm{COOCH}_{3}, \mathrm{CN}, \mathrm{CHO}$ and $\mathrm{CH}=\mathrm{CH}_{2}$. The slopes of the regression lines determined by the points for the alkyl or substituted alkyl groups $(\square)$ are $-3.5 \times 10^{-4}$ mol kcal ${ }^{-1}$ (A) and $3.0 \times 10^{-3} \mathrm{~mol} \mathrm{kcal}^{-1}$ (B). Data obtained by $A M 1$ calculations as described in the text.

although the values of $c_{\text {SOMo }}^{2}$ are lowered by approximately 0.05 as a result of the presence of the two tertbutyl groups. Also in this case, the points for $\mathrm{R}=\mathrm{CHO}$, $\mathrm{COOCH}_{3}$ and $\mathrm{CN}$ fall close to the regression line defined by the alkyl-type substituents and the points for $\mathrm{R}=$ vinyl and $\mathrm{COCH}_{3}$ deviate as described for $\mathrm{C}-1$.

Essentially the same pattern as described for the unpaired electron density is observed for the net atomic charges, $q$ (Figs. 15A and 15B).

9-Substituted anthracenes. The results for a series of 9substituted anthracenes (5) are summarized in Figs. 16 and 17. The tendencies are similar to those observed from the 1-substituted-2,6-di-tert-butylbenzenes for both $c_{\text {SOMo }}^{2}$ and $q$. It is seen that $c_{\text {Somo }}^{2}$ and $-q$ both increases at $\mathrm{C}-9$ and decreases at $\mathrm{C}-10$ with decreasing values of $\Delta \Delta H_{\mathrm{f}}$. It is also seen that the $\pi$-type substituents $(\mathbf{\Delta})$ in general fall close to the regression line defined by the alkyl-like substituents ( $\boldsymbol{\square}$ ) illustrating that conjugational effects are only small. In this case the steric hindrance of coplanarity of the $\pi$-systems is caused by the hydrogen atoms in the 1- and 8-positions. The opposing trends for $c_{\text {SOMo }}^{2}$ at C-9 and C-10 has the effect that the value of $c_{\text {SOMo }}^{2}$ at C-9 is approximately three times as big as that 


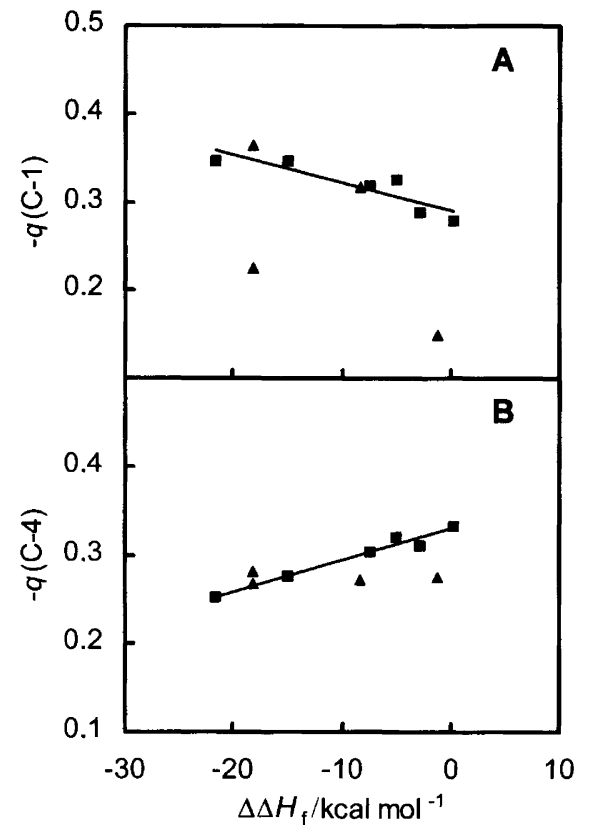

Fig. 15. Values of the net atomic charge, $q$, at $\mathrm{C}-1$ (A) and C-4 (B) vs. $\Delta \Delta H_{f}\left(=\Delta H_{f}^{\text {radical anion }}-\Delta H_{f}^{\text {substrate }}\right)$ for the radical anions of 1-substituted 2,6-di-tert-butylbenzenes (4). The data points refer to the same substituents and calculations as in Fig. 14. The slopes of the regression lines determined by the points for the alkyl or substituted alkyl groups (D) are $-3.2 \times 10^{-3} \mathrm{~mol} \mathrm{kcal}^{-1}(\mathrm{~A})$ and $3.6 \times 10^{-3} \mathrm{~mol} \mathrm{kcal}^{-1}(\mathrm{~B})$.

at $\mathrm{C}-10$ for the anthracene derivative $\left(\mathrm{R}=\mathrm{NO}_{2}\right)$ predicted to be the most easily reduced.

Esters of acrylic acid and cinnamic acid. The acrylic acid esters (6) and the cinnamic acids esters (7) are different from the model compounds discussed so far as the changes in substitution take place in a part of the molecule (the alcohol part) that formally is not in conjugation with the unsaturated ester $\pi$-system. In that sense the radical anions of 6 and 7 are related to those of, e.g., aromatic ethers ${ }^{72}$ and $\alpha$-aryloxyacetophenones. ${ }^{73}$ Common to the esters is also that they exist in two different conformations with dihedral $\mathrm{C}=\mathrm{C}-\mathrm{C}=\mathrm{O}$ angles equal to approximately $0^{\circ}$ and $180^{\circ}$. The calculations show that these two conformations are of similar energies and for the sake of consistency the calculations reported below all refer to an angle of $180^{\circ}$ (cf. Scheme 12).

The results obtained for the acrylates are shown in Figs. 18 and 19. By comparison of the results in Figs. $18 \mathrm{~A}, \mathrm{~B}$ and $\mathrm{C}$ it is seen that $c_{\text {somo }}^{2}$ at $\mathrm{C}-1$ increases, whereas $c_{\text {Somo }}^{2}$ at $\mathrm{C}-2$ and $\mathrm{C}-3$ decreases with decreasing values of $\Delta \Delta H_{\mathrm{f}}$ for $\mathrm{R}$ being alkyl or substituted alkyl (ם). The highest values, but the smallest substituent effects, are observed at the hypothetical position for dimerization, C-3. Similar trends are observed when the substituents are of the $\pi$-type $(\boldsymbol{\Delta})$, but the values observed at $\mathrm{C}-1$ are now significantly higher, and at C-2 and C-3 significantly lower, than those observed for $\mathrm{R}$ equal to alkyl or substituted alkyl. It is of interest to note that

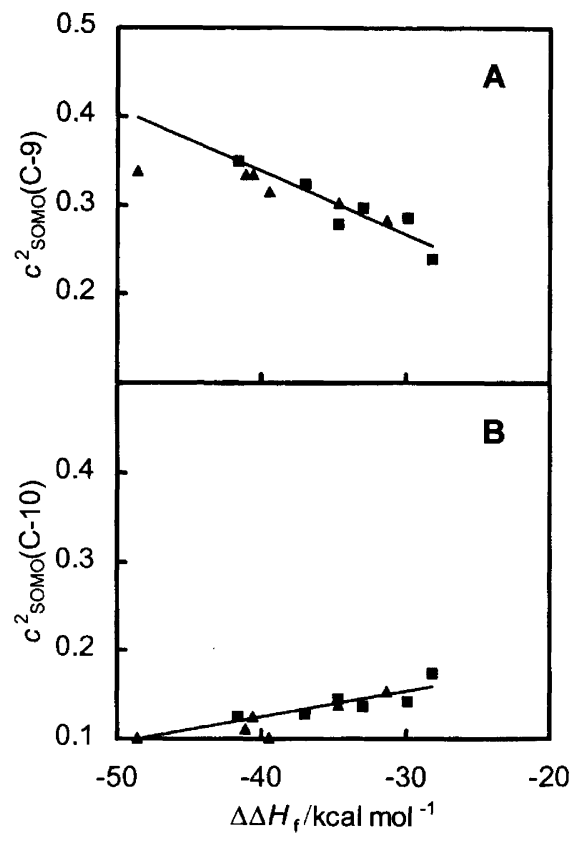

Fig. 16. Values of the unpaired electron density, $c_{\text {Somo, }}^{2}$ at $\mathrm{C}-9$ (A) and C-10 (B) vs. $\Delta \Delta H_{f}\left(=\Delta H_{f}^{\text {radical anion }}-\Delta H_{f}^{\text {substrate }}\right)$ for the radical anions of monosubstituted anthracenes (5). The data points shown as filled squares ( $\boldsymbol{D}$ ) are for alkyl or substituted alkyl groups and include (from left to right) $\mathrm{CF}_{3}$, $\mathrm{CHF}_{2}, \mathrm{CH}_{2} \mathrm{NH}_{2}, \mathrm{CH}_{2} \mathrm{~F}, \mathrm{CH}_{2} \mathrm{OH}$ and $\mathrm{CH}_{3}$. The data points shown as filled triangles $(\mathbf{\Lambda})$ are for $\pi$-type substituents and include (from left to right) $\mathrm{NO}_{2}, \mathrm{CN}, \mathrm{COOCH}_{3}, \mathrm{CHO}, \mathrm{COCH}_{3}$ and $\mathrm{CH}=\mathrm{NH}$. The slopes of the regression lines determined by the points for the alkyl or substituted alkyl groups ( $\square$ ) are $-7.1 \times 10^{-3} \mathrm{~mol} \mathrm{kcal}^{-1}$ (A) and $2.9 \times 10^{-3} \mathrm{~mol} \mathrm{kcal}^{-1}$ (B). Data obtained by AM1 calculations as described in the text.

regression lines defined by $c_{\text {SOMo }}^{2}$ and $\Delta \Delta H_{\mathrm{f}}$ for the $\pi$-type substituents would in fact have slopes of similar magnitude to those observed for the alkyl like substituents. In a sense these three compounds may be considered as part of a subseries of 1,4-disubstituted benzenes. It is also of interest to note that the values of $c_{\text {Somo for one }}^{2}$ of the $\pi$-type substituents, vinyl, are close to those expected for an alkyl-like substituent, illustrating that the acrylic acid ester is the more easily reduced of the two $\pi$-systems and therefore that the introduction of a remote vinyl substituent for this series of radical anions may be considered as a small perturbation only.

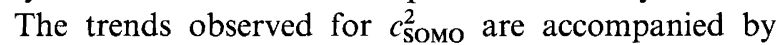
similar trends for $-q$ as seen in Fig. 19.

Intuitively (or naively) it might have been expected that the results obtained for the radical anions of the cinnamates, 7, would be similar to those for the radical anions of the corresponding acrylates considering that the only difference between the two series of compounds is the presence of the phenyl group in the 3-position in the cinnamates. However, significant differences were observed.

The results are shown in Figs. 20 and 21. On comparison of the values of $c_{\text {SOMo }}^{2}$ at $\mathrm{C}-1$ for the radical anions of the acrylates (Fig. 18A) and the cinnamates (Fig. 20A) 


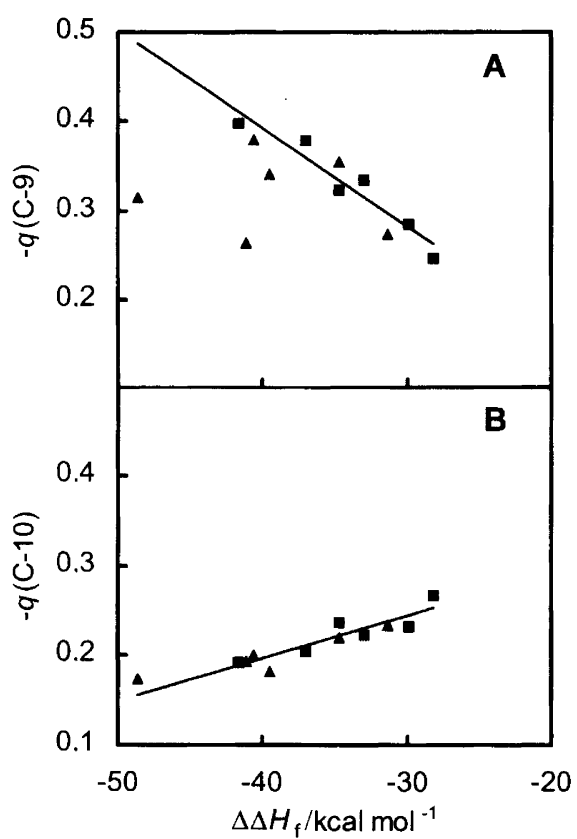

Fig. 17. Values of the net atomic charge, $q$, at C-9 (A) and C-10 (B) vs. $\Delta \Delta H_{f}\left(=\Delta H_{f}^{\text {radical anion }}-\Delta H_{f}^{\text {substrate }}\right)$ for the radical anions of monosubstituted anthracenes (5). The data points refer the same substituents and calculations as in Fig. 16. The slopes of the regression lines determined by the points for the alkyl or substituted alkyl groups $(\square)$ are $-1.1 \times 10^{-2}$ $\mathrm{mol} \mathrm{kcal}{ }^{-1}(\mathrm{~A})$ and $4.7 \times 10^{-3} \mathrm{~mol} \mathrm{kcal}^{-1}(\mathrm{~B})$.

it is seen that $c_{\text {SOMO }}^{2}$ in both cases increases with decreasing values of $\Delta \Delta H_{\mathrm{f}}$, but for the cinnamates the points for all the aryl esters $(\Delta)$ fall close to the regression line defined by the esters derived from aliphatic alcohols $(\boldsymbol{\square})$. Thus, we have now reached the point where the electron affinity for the unsaturated ester $\pi$-system is higher than that of even the 4-cyanophenoxy system and accordingly all the $\mathrm{R}$ groups in this series may be considered as small perturbations of the $\pi$-system of the ester. At C-2, which carries the highest unpaired electron density, the values of $c_{\text {Somo }}^{2}$ are essentially independent of the nature of $\mathrm{R}$ (Fig. 20B). This is in contrast with the acrylates (Fig. 18B) for which the values of $c_{\text {Somo }}^{2}$ at $\mathrm{C}-2$ were smaller than those at $\mathrm{C}-3$ and in addition found to decrease with decreasing values of $\Delta \Delta H_{\mathrm{f}}$. The most important difference between the two series is observed at $\mathrm{C}-3$, which for the cinnamates is known to be the position of dimerization. For the cinnamate radical anions (Fig. 20C), $c_{\text {SOMO }}^{2}$ is observed to increase with decreasing values of $\Delta \Delta H_{\mathrm{f}}$, whereas the opposite trend was observed for the acrylate radical anions (Fig. 18C).

General trends and implications. The number of model compounds included in the seven series, 1-7, amounts to 93 and to the best of our knowledge this is the largest set of theoretical data for radical anions yet available. Some general trends have become apparent during the calculations.

As expected it was found for all of the seven series

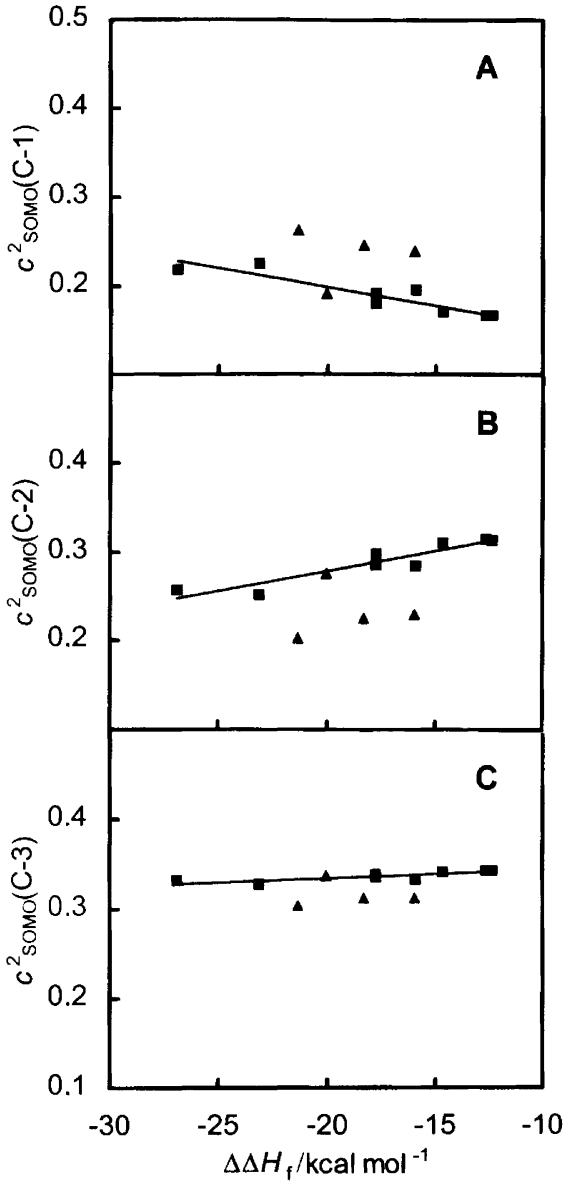

Fig. 18. Values of the unpaired electron density, $C_{\text {Somo, }}^{2}$ at C-1 (A), C-2 (B) and C-3 (C) vs. $\Delta \Delta H_{f}$ $\left(=\Delta H_{f}^{\text {radical anion }}-\Delta H_{f}^{\text {substrate }}\right)$ for the radical anions of acrylic acid esters (6). The data points shown as filled squares ( $\square$ ) are for alkyl or substituted alkyl groups and include (from left to right) $\mathrm{CF}_{3}, \mathrm{CHF}_{2}, \mathrm{CH}_{2} \mathrm{OH}, \mathrm{CH}_{2} \mathrm{~F}, \mathrm{CH}_{2} \mathrm{OCH}_{3}, \mathrm{CH}_{2} \mathrm{NH}_{2}$, $\mathrm{CH}_{3}$ and $\mathrm{CH}_{2} \mathrm{CH}_{3}$. The data points shown as filled triangles $(\Delta)$ are for $\pi$-type substituents and include (from left to right) $\mathrm{C}_{6} \mathrm{H}_{4} \mathrm{CN}(p-), \mathrm{CH}=\mathrm{CH}_{2}, \mathrm{C}_{6} \mathrm{H}_{4} \mathrm{OCH}_{3}(p-)$ and $\mathrm{C}_{6} \mathrm{H}_{5}$. The slopes of the regression lines determined by the points for the alkyl or substituted alkyl groups ( $\boldsymbol{\square})$ are $-4.1 \times 10^{-3} \mathrm{~mol} \mathrm{kcal}^{-1}$ (A), $4.5 \times 10^{-3} \mathrm{~mol} \mathrm{kcal}^{-1}$ (B) and $9.2 \times 10^{-4} \mathrm{~mol} \mathrm{kcal}^{-1}$ (C). The data were obtained by AM1 calculations as described in the text and refer to the conformation in which the dihedral $\mathrm{C}=\mathrm{C}-\mathrm{C}=\mathrm{O}$ angle is close to $180^{\circ}$ as indicated by the structure, 6.

that the substitution of a hydrogen atom with an alkyllike substituent is only a small perturbation of the parent $\pi$-system and, accordingly, the values of $c_{\text {Somo }}^{2}$ and $q$ depend essentially linearly on $\Delta \Delta H_{\mathrm{f}}$. The same is true for the $\pi$-type substituents as long as the conjugation between the $\pi$-systems of the substituent and the parent compound is only small as observed for some of the 1substituted-2,6-di-tert-butylbenzenes, the 9-substituted anthracenes and, of course, the acrylic and cinnamic acid esters.

Less obvious is the magnitude of the effects. In particular, it is of interest to note that for the benzene and the anthracene series both $c_{\text {Somo }}^{2}$ and $q$ take the highest 


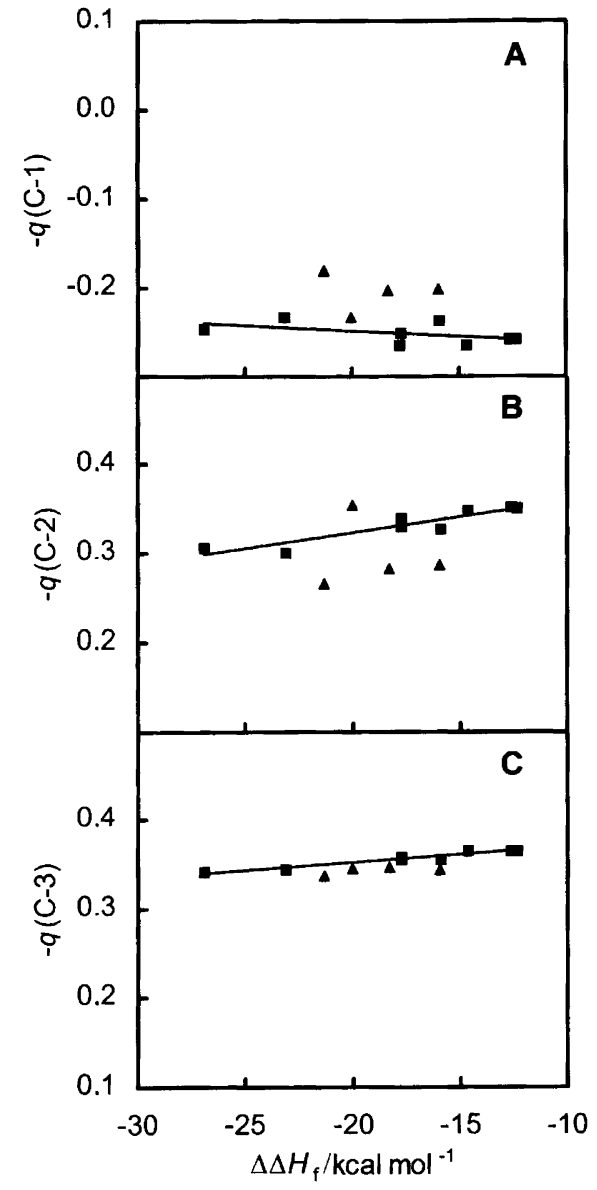

Fig. 19. Values of the net atomic charge, $q$, at $\mathrm{C}-1$ (A), C-2 (B) and C-3 (C) vs. $\Delta \Delta H_{f}\left(=\Delta H_{f}^{\text {radical anion }}-\Delta H_{f}^{\text {substrate }}\right)$ for the radical anions of acrylic acid esters (6). The data points refer to the same substituents and calculations as in Fig. 18. The slopes of the regression lines determined by the points for the alkyl or substituted alkyl groups ( $\square$ ) are $-1.2 \times 10^{-3}$ $\mathrm{mol} \mathrm{kcal}^{-1}$ (A), $3.6 \times 10^{-3} \mathrm{~mol} \mathrm{kcal}^{-1}$ (B) and $1.8 \times 10^{-3}$ mol kcal ${ }^{-1}(\mathrm{C})$.

values at the carbon carrying the substituents, that is C-1 and C-9, respectively. For the benzene radical anions this is in agreement with the earlier observation that the molecular electrostatic potential maps often showed a minimum at $\mathrm{C}-1$ deeper than that at $\mathrm{C}-4 .{ }^{71 \mathrm{c}}$ For the anthracenes it is known that dimerization takes place through the 10 -position and both for the benzenes ${ }^{71 b, c}$ and the anthracenes it would be expected that the first step in the reaction with an electrophile, e.g., a proton donor, involves preferentially $\mathrm{C}-4$ and $\mathrm{C}-10$, respectively, rather than C-1 and C-9. Thus, we may conclude already at this stage that the kinetics and distribution of products observed experimentally are not simple functions of $c_{\text {SOMo }}^{2}$ and $q$ at the carbons through which reaction takes place. Similarly, it is seen for the cinnamate radical anions that the highest values of $c_{\text {somo }}^{2}$ and $q$ are found at $\mathrm{C}-2$ although it is known that dimerization takes place through C-3. We return to a possible implication of these

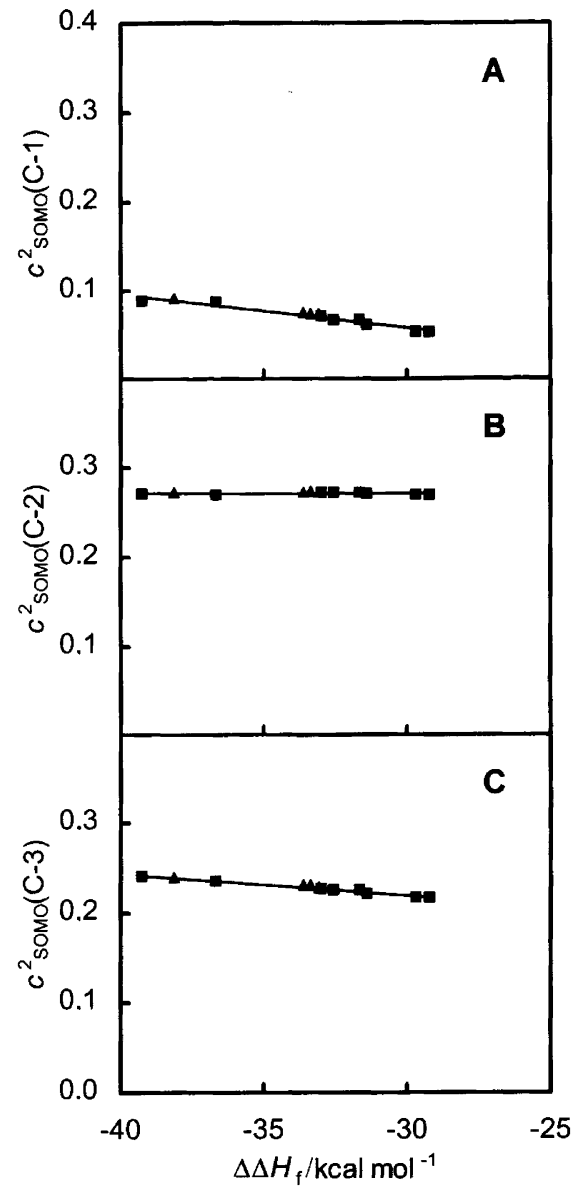

Fig. 20. Values of the unpaired electron density, $C_{\text {Somo, }}^{2}$ at $\mathrm{C}-1 \quad$ (A), $\quad \mathrm{C}-2 \quad$ (B) and $\mathrm{C}-3 \quad$ (C) vs. $\Delta \Delta H_{\mathrm{f}}$ $\left(=\Delta H_{f}^{\text {radical anion }}-\Delta H_{f}^{\text {substrate }}\right)$ for the radical anions of cinnamic acid esters (7). The data points shown as filled squares (D) are for alkyl or substituted alkyl groups and include (from left to right) $\mathrm{CF}_{3}, \mathrm{CHF}_{2}, \mathrm{CH}_{2} \mathrm{OH}, \mathrm{CH}_{2} \mathrm{~F}, \mathrm{CH}_{2} \mathrm{OCH}_{3}$, $\mathrm{CH}_{2} \mathrm{NH}_{2}, \mathrm{CH}_{3}$ and $\mathrm{CH}_{2} \mathrm{CH}_{3}$. The data points shown as filled triangles $(\boldsymbol{\Delta})$ are for $\pi$-type substituents and include (from left to right) $\mathrm{C}_{6} \mathrm{H}_{4} \mathrm{CN}(p-), \mathrm{C}_{6} \mathrm{H}_{5}, \mathrm{C}_{6} \mathrm{H}_{4} \mathrm{OCH}_{3}(p-)$ and $\mathrm{CH}=\mathrm{CH}_{2}$. The slopes of the regression lines determined by the points for the alkyl or substituted alkyl groups (D) are $-4.0 \times 10^{-3}$ $\mathrm{mol} \mathrm{kcal}^{-1}$ (A), $-2.0 \times 10^{-5} \mathrm{~mol} \mathrm{kcal}^{-1}$ (B) and $-2.4 \times 10^{-3}$ $\mathrm{mol} \mathrm{kcal}^{-1}$ (C). Data obtained by AM1 calculations, as described in the text, refer to the conformation in which the dihedral $\mathrm{C}=\mathrm{C}-\mathrm{C}=\mathrm{O}$ angle is close to $180^{\circ}$ as indicated by the structure, 7 .

trends below in the discussion of the experimental results for the anthracenes and the cinnamates.

\section{The reaction series discussed in Sections II and III}

The results obtained for the compounds not belonging to the series of model compounds are presented in tabular form and for each series arranged according to increasing values of $\Delta \Delta H_{\mathrm{f}}$.

Methyl substituted N-ethylmaleimides (Scheme 8, Fig. 3). Related to the ethylene model compounds are the three 


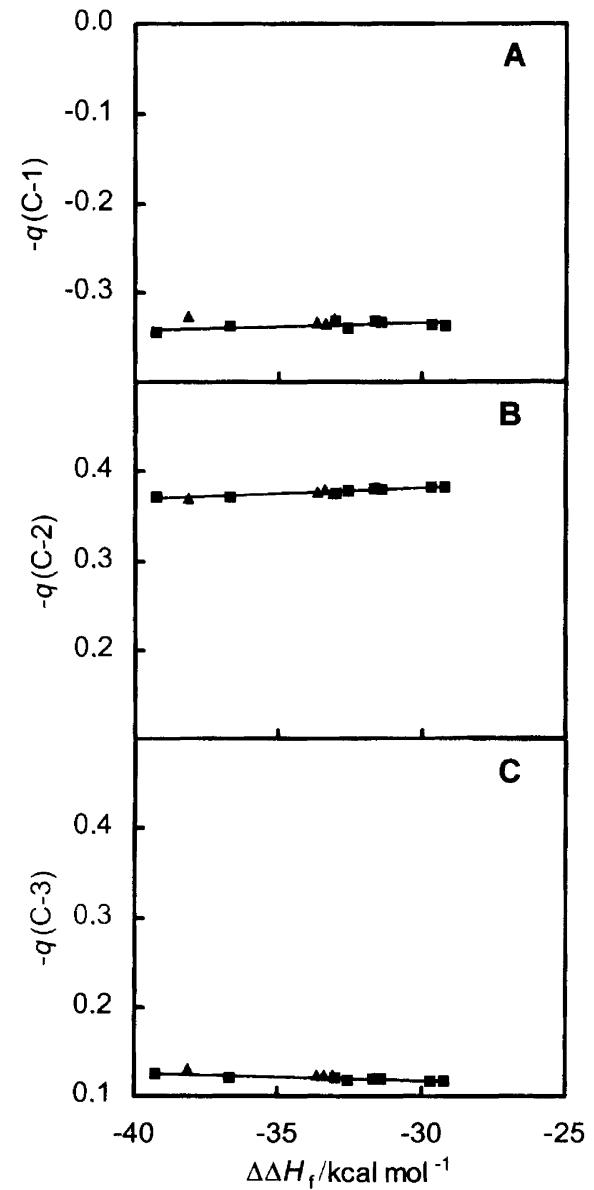

Fig. 21. Values of the net atomic charge, $q$, at C-1 (A), C-2 (B) and C-3 (C) vs. $\Delta \Delta H_{\mathrm{f}}\left(=\Delta H_{\mathrm{f}}^{\text {radical anion }}-\Delta H_{\mathrm{f}}^{\text {substrate }}\right)$ for the radical anions of cinnamic acid esters (7). The data points refer to the same substituents and calculations as in Fig. 20. The slopes of the regression lines determined by the points for the alkyl or substituted alkyl groups ( 1 ) are $7.5 \times 10^{-4}$ $\mathrm{mol} \mathrm{kcal}^{-1}$ (A), $1.3 \times 10^{-3} \mathrm{~mol} \mathrm{kcal}^{-1}$ (B) and $-7.5 \times 10^{-4}$ $\mathrm{mol} \mathrm{kcal}^{-1}$ (C)

$N$-ethylmaleimides. The results obtained by AM1 calculations are summarized in Table 1 . The calculated difference between $\Delta \Delta H_{\mathrm{f}}$ for the dimethyl substituted and the unsubstituted compound amounts to only $1.5 \mathrm{kcal} \mathrm{mol}^{-1}$ corresponding to approximately $65 \mathrm{mV}$. Thus, the substitution of two hydrogens with methyl in $N$-ethylmaleimide is indeed only a small perturbation and therefore it is somewhat unexpected that the difference in $E_{1 / 2}$ observed experimentally is as large as $250 \mathrm{mV}$ (Fig. 3). However, the calculations also show that the increase in net atomic negative charges upon reduction to the radical anions takes place mainly at the ethylenic carbons, C-1 and C-2, and the two carbonyl oxygens, O-1 and O-2. Thus, the large difference observed in $E_{1 / 2}$ most likely reflects that the gain in solvation energy that accompanies the formation of the radical anion of the dimethyl derivative is slightly reduced owing to the steric hindrance to solvation imposed by the two methyl groups close to the centers of negative charge.

Comparison of the data in Table 1 shows that the unpaired electron density at $\mathrm{C}-1$ and $\mathrm{C}-2$ is lower for $\mathrm{R}, \mathrm{R}^{\prime}=\mathrm{CH}_{3}, \mathrm{CH}_{3}$ than for $\mathrm{R}, \mathrm{R}^{\prime}=\mathrm{H}, \mathrm{H}$ and that the highest value of $c_{\text {Somo }}^{2}$ is found at $\mathrm{C}-1$ for the unsymmetrically substituted derivative, $\mathrm{R}, \mathrm{R}^{\prime}=\mathrm{CH}_{3}, \mathrm{H}$. However, the differences are only small and, even considering the statistical correction required in comparison with the relative rates for dimerization of symmetrical and unsymmetrical radical anions, it is not obvious from these data that the rate of dimerization would tend to decrease on passing from the most easily to the least easily reduced substrate, i.e., from $R, R^{\prime}=H, H$ to $R, R^{\prime}=C_{3}, C H_{3}$. Hence it appears most likely that the transition from predominantly dimerization for $\mathrm{R}, \mathrm{R}^{\prime}=\mathrm{H}, \mathrm{H}$ to predominantly protonation for $\mathrm{R}, \mathrm{R}^{\prime}=\mathrm{CH}_{3}, \mathrm{CH}_{3}$ is caused by an increased rate of protonation of the radical anions, mainly governed by the increased values of $E_{\text {LUMO }}$.

For the unsymmetrically substituted compound it was observed that dimerization takes place through $\mathrm{C}-1$, that is the carbon carrying the methyl substituent. This is good agreement with the AM1 results that predict that the higher unpaired electron density is indeed observed at C-1.

$\beta$-Methylstyrenes (Scheme 9, Fig. 4). The experimental data for this series of compounds have to be treated with

Table 1. Results from AM1 calculations for $N$-ethylmaleimides and the corresponding radical anions. ${ }^{a}$<smiles>[R]C1=C([R])C(=O)N(CC)C1=O</smiles>

\begin{tabular}{llllllllll}
\hline $\mathrm{R}$ & $\mathrm{R}$ & $\Delta \Delta H_{\mathrm{f}}$ & $E_{\text {LUMO }}$ & $\begin{array}{l}c_{\text {SOMo }}^{2} \\
(\mathrm{C}-1)\end{array}$ & $\begin{array}{c}c_{\text {SOMO }}^{2} \\
(\mathrm{C}-2)\end{array}$ & $\begin{array}{c}-q \\
(\mathrm{C}-1)\end{array}$ & $\begin{array}{c}-q \\
(\mathrm{C}-2)\end{array}$ & $\begin{array}{c}-q \\
(\mathrm{O}-1)\end{array}$ & $\begin{array}{c}-q \\
(\mathrm{O}-2)\end{array}$ \\
\hline $\mathrm{H}$ & $\mathrm{H}$ & -40.5 & -1.094 & 0.307 & 0.307 & 0.338 & 0.339 & 0.467 & 0.463 \\
$\mathrm{CH}_{3}$ & $\mathrm{H}$ & -39.8 & -1.023 & 0.314 & 0.292 & 0.291 & 0.334 & 0.459 & 0.462 \\
$\mathrm{CH}_{3}$ & $\mathrm{CH}_{3}$ & -39.0 & -0.959 & 0.299 & 0.300 & 0.285 & 0.286 & 0.458 & 0.455 \\
\hline
\end{tabular}

${ }^{a} \Delta \Delta H_{\mathrm{f}}=\Delta H_{\mathrm{f}}^{\text {radical anion }}-\Delta H_{\mathrm{f}}^{\text {substrate }} ; E_{\mathrm{Lumo}}$ is the energy (in $\mathrm{eV}$ ) of the lowest unoccupied molecular orbital of the neutral

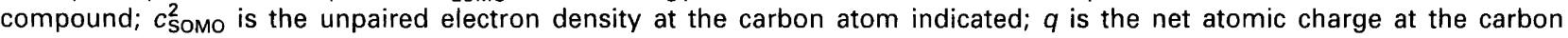
indicated. 
caution as the $\beta$-methylstyrenes result from the in situ isomerization of the corresponding allylbenzenes induced by electrochemically generated base. Since the concentration of base necessary for the onset of the isomerization obviously depends on the substitution in the phenyl ring, the $\beta$-methylstyrene radical anion concentration will not be directly related to the passage of current through the electrolysis cell. This in turn means that the competition between the second-order dimerization and the pseudofirst-order protonation, and hence the product distribution, is not necessarily a simple function of the substitution pattern. In addition, the series encompasses only one substrate having a strongly electron withdrawing substituent (4-CN) and for the remaining substituents the position of substitution is not even restricted to the 4-position. We have, nevertheless, carried out AM1 calculations for these compounds as well and the results are shown in Table 2.

First it is noted that $\Delta \Delta H_{\mathrm{f}}$ does not vary with substitution as expected ${ }^{31}$ (see Fig. 4). In particular, we have assumed in the construction of Fig. 4 that the $\beta$-methylstyrenes carrying alkoxy type substituents would be more difficult to reduce than predicted from $\Delta \Delta H_{\mathrm{f}}$. This most likely reflects that $\Delta \Delta G_{\text {solv }}$ does not necessarily change in a gradual fashion on passing from, e.g., 4-CN to $3-\mathrm{CH}_{3}$.

The calculations show that the highest unpaired electron density is located at the carbon in the benzene ring carrying the more electronegative $\pi$-type substituent, that is at $\mathrm{C}-4$ for the 4-cyanoderivative and at $\mathrm{C}-1$ for the remaining compounds in agreement with results obtained for the benzene series. At $C-\beta$, the carbon through which dimerization takes place, the values of $c_{\text {SOMo }}^{2}$ are somewhat lower and found to increase slightly with (predicted) decreasing ease of reduction of the $\beta$-methylstyrene. The highest values of $-q$ are located at the position for protonation, $C-\beta$, and are, except for $\mathrm{R}=4$ $\mathrm{CN}$, essentially independent on substitution. Thus, although both the unpaired electron density and the net atomic charge is high at $\mathrm{C}-\beta$ the theoretical data are of little help in explaining the rather abrupt change in the product distribution, from predominantly dimerization to predominantly protonation, observed on passing from $3-\mathrm{CH}_{3}$ to $4-\mathrm{CH}_{3}$.

9-Substituted anthracenes (Scheme 10, Fig. 5). The AM1 calculations for the anthracene series predict that the unpaired electron density at C-10 (Fig. 16B) decreases with increasing ease of reduction, although there is some scatter in the theoretical data in the region of low $\Delta \Delta H_{\mathrm{f}}$ where the substituents of the three anthracenes $(R=$ $\mathrm{NO}_{2}, \mathrm{CHO}$ and $\mathrm{CN}$ ) studied experimentally are located. In contrast, the values of $c_{\text {Somo }}^{2}$ at C-9 (Fig. 16A) increase with increasing ease of reduction and, in addition, are significantly larger than those at $\mathrm{C}-10$. Thus, if the rate of dimerization is largely determined by the unpaired electron density in the 10-position it would be expected that $k_{\text {dim }}$ should decrease with increasing ease of reduction of the anthracene. The opposite trend was observed experimentally. The values of $\log k_{\text {dim }}$ were found to increase with increasing values of $\sigma^{-}$(Fig. 5), and hence with increasing ease of reduction of the anthracenes, and apparently there seems to be no direct relationship between the theoretical and the experimental data. However, it should be recalled that a characteristic of these dimerization processes is that the enthalpies of activation are much lower than expected for a reaction proceeding as a simple one-step process. This observation led to the suggestion ${ }^{32}$ that the dimerization proceeds as a two-step process involving initially the formation of a $\pi$-complex, ${ }^{-} \mathrm{XA} / \mathrm{AX}^{-}$[eqn. (9)], and then the formation of the $\sigma$-bond between the two carbons in the 10 position [eqn. (10)].

$$
\begin{aligned}
& 2 \mathrm{AX}^{\cdot-} \underset{k_{-9}}{\stackrel{k_{9}}{\rightleftharpoons}}-\mathrm{XA} / \mathrm{AX}^{-} \quad\left(K_{9}=k_{9} / k_{-9}\right) \\
& -\mathrm{XA} / \mathrm{AX}^{-} \underset{k_{-10}}{\stackrel{k_{10}}{\rightleftharpoons}}-\mathrm{XA}-\mathrm{AX}^{-} \quad\left(K_{10}=k_{10} / k_{-10}\right)
\end{aligned}
$$

Table 2. Results from AM1 calculations for $\beta$-methylstyrenes and the corresponding radical anions. ${ }^{a}$

\begin{tabular}{|c|c|c|c|c|c|c|c|c|c|c|}
\hline$x$ & $\Delta \Delta H_{\mathrm{f}}$ & $E_{\text {LUMO }}$ & $\begin{array}{l}c_{\text {SOMo }}^{2} \\
(\mathrm{C}-\alpha)\end{array}$ & $\begin{array}{l}c_{\text {Sомо }}^{2} \\
(\mathrm{C}-\beta)\end{array}$ & $\begin{array}{l}c_{\text {SOMo }}^{2} \\
(\mathrm{C}-1)\end{array}$ & $\begin{array}{l}c_{\text {Somo }}^{2} \\
(\mathrm{C}-4)\end{array}$ & $\begin{array}{l}-q \\
(C-\alpha)\end{array}$ & $\begin{array}{l}-q \\
(C-\beta)\end{array}$ & $\begin{array}{l}-q \\
(C-1)\end{array}$ & $\begin{array}{l}-q \\
(\mathrm{C}-2)\end{array}$ \\
\hline $\mathrm{CN}$ & -26.3 & -0.702 & 0.073 & 0.112 & 0.189 & 0.236 & 0.114 & 0.295 & 0.121 & 0.225 \\
\hline $\mathrm{OCH}_{2} \mathrm{O}^{b}$ & -16.0 & -0.161 & 0.113 & 0.182 & 0.225 & 0.165 & 0.127 & 0.341 & 0.150 & 0.148 \\
\hline $\mathrm{OCH}_{3}$ & -12.1 & 0.054 & 0.118 & 0.174 & 0.210 & 0.180 & 0.132 & 0.340 & 0.143 & 0.131 \\
\hline $\mathrm{C}\left(\mathrm{CH}_{3}\right)_{3}$ & -10.7 & 0.084 & 0.129 & 0.183 & 0.207 & 0.173 & 0.140 & 0.345 & 0.133 & 0.227 \\
\hline $\mathrm{CH}_{3}$ & -10.3 & 0.010 & 0.132 & 0.186 & 0.205 & 0.171 & 0.142 & 0.349 & 0.133 & 0.237 \\
\hline $\mathrm{H}$ & -9.6 & 0.022 & 0.141 & 0.197 & 0.206 & 0.159 & 0.149 & 0.353 & 0.128 & 0.279 \\
\hline $\mathrm{CH}_{3}{ }^{\mathrm{c}}$ & -9.4 & 0.095 & 0.138 & 0.196 & 0.209 & 0.158 & 0.145 & 0.352 & 0.133 & 0.269 \\
\hline
\end{tabular}

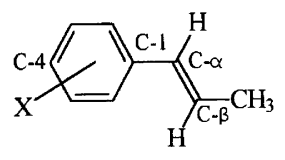

${ }^{a} \Delta \Delta H_{\mathrm{f}}=\Delta H_{\mathrm{f}}^{\text {radical anion }}-\Delta H_{\mathrm{f}}^{\text {substrate }} ; E_{\mathrm{Lumo}}$ is the energy (in $\mathrm{eV}$ ) of the lowest unoccupied molecular orbital of the neutral compound; $c_{\text {Somo }}^{2}$ is the unpaired electron density at the carbon atom indicated; $q$ is the net atomic charge at the carbon indicated. The substituents are attached to the 4-position unless otherwise indicated. ${ }^{b} 3,4$-Substituent. ${ }^{c} 3$-Substituent. 


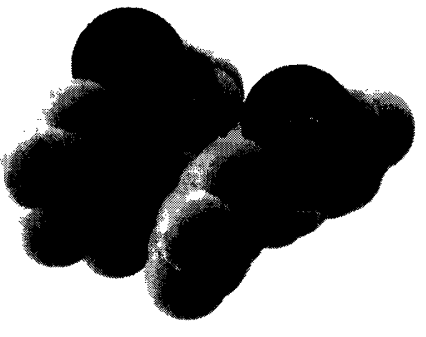

8

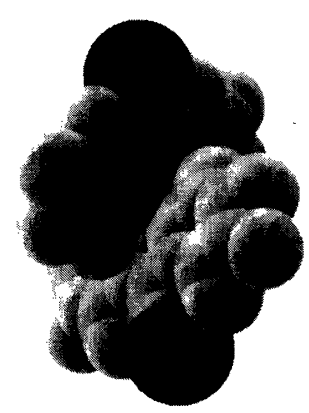

9

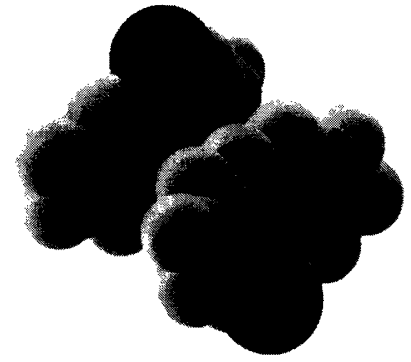

10

Scheme 13.

With high unpaired electron densities at C-9 in mind it is tempting to suggest that the $\pi$-complex results from an interaction between the two radical anions that initially involves the carbons in both the 9- and the 10positions resulting in a sandwich-like structure reminiscent of that of anthracene photodimers. ${ }^{74}$ The subsequent formation of the $\sigma$-bond would then lead to the $10,10^{\prime}$ dimer dianion, possibly in the first place with a conformation (8) similar to that of the $\pi$-complex, which then relaxes by rotation around the $10,10^{\prime}$-bond resulting in one or both of the stable conformations, 9 and $\mathbf{1 0}$. The structures of $\mathbf{8}, \mathbf{9}$, and $\mathbf{1 0}$ are shown in Scheme 13. Preliminary AM1 calculations for the dimer dianion of the 9-cyanoanthracene radical anion show that $\mathbf{8}$ does indeed represent an energy minimum $\left(\Delta H_{\mathrm{f}}=\right.$ $161.7 \mathrm{kcal} \mathrm{mol}^{-1}$ ) and that 9 and 10 represent conformations of the dimer dianion with similar heats of formation $\left(\Delta H_{\mathrm{f}}=142 \mathrm{kcal} \mathrm{mol}^{-1}\right.$ for $9 ; \Delta H_{\mathrm{f}}=143.7 \mathrm{kcal} \mathrm{mol}^{-1}$ for 10). More advanced calculations are now in progress. ${ }^{75}$

The formation of a $\pi$-complex is a fast and reversible process with a rather small value of $K_{9}$ and, accordingly, the equilibrium approximation may be applied for reaction (9) in deriving the rate law. This takes the form of eqn. (11) under conditions where the dissociation of the dimer dianion may be neglected. It follows from the discussion above that the interaction in the $\pi$-complex is highly dependent on the unpaired electron density in the 9-position and thus it would be expected that the value of $K_{9}$ is largely determined by the magnitude of $c_{\text {Sомо }}^{2}$ in this position. This would indeed explain the observed relationship between $\log k_{\mathrm{dim}}$ and the ease of reduction of the anthracenes.

$$
-\mathrm{d}\left[\mathrm{AX}^{\cdot-1+}\right] / \mathrm{d} t=2 K_{9} k_{10}\left[\mathrm{AX}^{\cdot-1+}\right]^{2}=k_{\mathrm{dim}}\left[\mathrm{AX}^{\cdot-1+}\right]^{2}
$$

Cinnamic acid esters (Schemes 3 and 5, Figs. 1 and 2). As already mentioned in Section II, a major reason for our present interest in possible correlations between kinetic data and the electronic properties of radical ions was the observation that $\log k_{\mathrm{dim}}$ for the $\mathrm{RR}$-dimerization of the cinnamate radical anions in DMF is linearly related to the values of $c_{\text {SOMo }}^{2}$ at $\mathrm{C}-3$.

However, in this case we also find that $c_{\text {SOMo }}^{2}$ does not reach its maximum value at the carbon through which dimerization takes place. From Fig. 20B it is seen that $c_{\text {Sомо }}^{2}$ at the neighboring carbon $(\mathrm{C}-2)$ is actually somewhat higher, but essentially independent of the nature of the alcohol part of the ester. Similarly to what has been reported for the dimerization of the 9-substituted anthracene radical anions ${ }^{32}$ it was found that the dimerization of the cinnamate radical anions ${ }^{19 a}$ was accompanied by activation energies that appear to be too low for a simple bimolecular reaction with rate constants in the $10^{2}-10^{5} \mathrm{M}^{-1} \mathrm{~s}^{-1}$ range. This was taken as support for the view that the irreversible dimerization was preceded by a hydrogen-bond equilibrium (Scheme 3 ). However, following the reasoning made for the dimerization of the 9-substituted anthracene radical anions in a previous paragraph, we cannot rule out that the low activation energies for the dimerization of the cinnamate radical anions partly reflect a reaction profile that includes a $\pi$-complex, in this case owing to the high values of $c_{\text {Somo }}^{2}$ at $\mathrm{C}-2$.

The results obtained by the AM1 calculations do not directly provide an explanation of the observation that the radical anions of the alkyl cinnamates in $\mathrm{MeOH}$ are preferentially protonated whereas those derived from the aryl cinnamates tend to dimerize (Scheme 7). In addition, we see no clear relationship between $-q$ at the carbonyl oxygen and $\Delta \Delta H_{\mathrm{f}}$ (not included in Fig. 21). However, the results obtained for neutral compounds show that the charge density at the carbonyl oxygen for the alkyl cinnamates $(0.35-0.37)$ is slightly larger than that observed for the aryl cinnamates $(0.32-0.33)$. This may indicate that the equilibrium constant for hydrogen-bond formation between the neutral compounds and $\mathrm{MeOH}$ is also slightly larger for the alkyl cinnamates, which again may be related to the change in mechanism observed on passing from $\mathrm{R}=$ alkyl to $\mathrm{R}=$ aryl.

It was pointed out above that the AM1 results for the acrylates differ from those of the cinnamates in that the values of $c_{\text {Somo }}^{2}$ at C-3 (Fig. 18C) tend to decrease slightly rather than increase with decreasing values of $\Delta \Delta H_{\mathrm{f}}$ and, accordingly, that the rate of dimerization of acrylate radical anions would tend to decrease with increasing ease of reduction. We are not aware of experimental 
studies of the radical anions of a series of acrylates and have now undertaken an investigation aimed at testing this prediction. ${ }^{76}$

Dialkyl fumarates (Scheme 11, Fig. 6). The AM1 results for this series of compounds is shown in Table 3. It is seen that the effect of passing from $\mathrm{R}=\mathrm{CH}_{3}$ to $\mathrm{R}=$ $\mathrm{CH}_{3} \mathrm{CH}_{2} \mathrm{CH}_{2} \mathrm{CH}_{2}$ is even smaller than that observed for $\mathrm{N}$-ethylmaleimides, as also expected considering that the alkyl groups are situated at oxygens not formally in conjugation with the fumaric acid $\pi$-system. Thus, the observed differences in rate observed for both dimerization and the reaction with $\mathrm{CO}_{2}$ most likely reflect differences in steric hindrance caused by the conformational freedom of the longer alkyl groups, as also suggested in the original work. ${ }^{34,35}$

The relationship between the electronic properties of radical anions and their reactivity. It is is not possible at this stage to conclude whether the electronic properties obtained by semiempirical molecular orbital calculations for an isolated species in the gas phase may be used in general to predict the reactivity of radical anions in solution or if a more sophisticated approach, in the limit including a high level quantum mechanical treatment of the entire reaction profile under the influence of the solvent, is required. However, the observation that $\log k_{\text {dim }}$ (DMF) and $\log k_{\text {prot }}$ (DMF, phenol) for the cinnamates vary in the same fashion as $c_{\text {Somo }}^{2}$ at C-3 and $q$ at C-2, respectively, shows that results obtained by, e.g., AM1 calculations may be used with some confidence in discussions of the relative reactivity in a series radical anions for which the structural changes are limited to substituents that cause only a small perturbation of the parent $\pi$-system. Also, it appears safe to conclude that the formation of the new $\sigma$-bond during dimerization or reaction with an electrophile does not, as a rule, involve the carbon or heteroatom in the radical anion that carries

Table 3. Results from AM1 calculations for dialkyl fumarates and the corresponding radical anions. ${ }^{a}$<smiles>[R]OC(=O)/C=C\C(=O)O[R]</smiles>

\begin{tabular}{lrrrr}
\hline $\mathrm{R}$ & $\Delta \Delta H_{\mathrm{f}}$ & $E_{\text {LUMO }}$ & $c_{\text {SOMO }}^{2}$ & $-q$ \\
\hline $\mathrm{CH}_{3}$ & -38.9 & -1.000 & 0.326 & 0.292 \\
$\mathrm{CH}_{3} \mathrm{CH}_{2} \mathrm{CH}_{2} \mathrm{CH}_{2}$ & -38.6 & -0.925 & 0.326 & 0.293 \\
$\mathrm{CH}_{3} \mathrm{CH}_{2}$ & -38.1 & -0.928 & 0.327 & 0.293 \\
\hline
\end{tabular}

${ }^{a} \Delta \Delta H_{\mathrm{f}}=\Delta H_{\mathrm{f}}^{\text {radical anion }}-\Delta H_{\mathrm{f}}^{\text {substrate }} ; E_{\mathrm{LUMO}}$ is the energy (in $\mathrm{eV}$ ) of the lowest unoccupied molecular orbital of the neutral

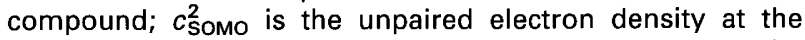
carbon atom indicated; $q$ is the net atomic charge at the carbon indicated. the highest values of $c_{\text {SOmo }}^{2}$ or $-q$ as illustrated by the results obtained for the 9-substituted anthracenes. The fact that the highest values of $c_{\text {Somo }}^{2}$ are often found in other positions may be the origin the positive interactions that lead to the intermediate formation of the $\pi$-complexes originally suggested to be the origin of the low activation energies often associated with radical anion dimerizations.

\section{Appendix}

The purpose of this appendix is to illustrate the problem of distinguishing between the RR- and the RSmechanism for processes leading to dimers via radical ions with a net consumption of charge.

Referring to the equations in Section IV, the first step of the RR-mechanism is given by eqn. (5), whereas the RS-mechanism includes eqns. (6)-(7), in both cases followed by a product forming step, eqns. $(8 \mathrm{a}),(8 \mathrm{~b})$ or (8c). Here we will discuss only the case where the substrate is not involved in the conversion of the doubly charged dimer, ${ }^{-1+} \mathrm{XA}-\mathrm{AX}^{-1+}$, to products and thus reaction $(8 \mathrm{c})$ may be neglected. Initially, we focus on the so-called limiting cases, these are processes the rates of which are controlled by a single irreversible step that may be proceeded by one or more steps for which the equilibrium approximation applies.

The rate laws associated with the limiting cases. The RR-mechanism gives rise to two limiting cases. Rate law (12) applies for the situation where the dimerization of the radical ions, eqn. (5), is irreversible and rate determining, and rate law (13a) for the situation where the dimerization is an equilibrium process and the further conversion of ${ }^{-1+} \mathrm{XA}-\mathrm{AX}^{-1+}$, eqn. (8a), is irreversible. If an additional reagent, $Y$, is needed for the latter reaction, eqn. (8a) is modified to eqn. (8b) and, accordingly, rate law (13a) to rate law (13b).

The RR-mechanism:

$$
\begin{aligned}
& -\mathrm{d}\left[\mathrm{AX}^{\cdot-1+}\right] / \mathrm{d} t=2 k_{5}\left[\mathrm{AX}^{\cdot-/+}\right]^{2} \\
& -\mathrm{d}\left[\mathrm{AX}^{\cdot-1+}\right] / \mathrm{d} t=2 K_{5} k_{8 \mathrm{a}}\left[\mathrm{AX}^{\cdot-/+}\right]^{2} \\
& -\mathrm{d}\left[\mathrm{AX}^{\cdot-1+}\right] / \mathrm{d} t=2 K_{5} k_{8 \mathrm{~b}}\left[\mathrm{AX}^{\cdot-/+}\right]^{2}[\mathrm{Y}]
\end{aligned}
$$

Similarly, the RS-mechanism gives rise to rate law (14) when the coupling between the radical ion and the substrate, eqn. (6), is irreversible and rate determining. When the coupling reaction is an equilibrium process and the electron transfer reaction, eqn. (7), is irreversible, rate law (15) applies. Finally, when both the coupling and the electron transfer reactions are equilibrium processes and the conversion of ${ }^{-1+} \mathrm{XA}-\mathrm{AX}^{-1+}$, eqns. (8a) or $(8 b)$, is irreversible, the kinetics are described by rate laws (16a) or (16b), again with (8b) and (16b) applying to the situation where $\mathrm{Y}$ is needed for the conversion of ${ }^{-1+} \mathrm{XA}-\mathrm{AX} \mathbf{X}^{-1+}$. 
The RS-mechanism:

$$
\begin{aligned}
&-\mathrm{d}\left[\mathrm{AX}^{\cdot-1+}\right] / \mathrm{d} t=k_{6}\left[\mathrm{AX}^{\cdot-1+}\right][\mathrm{AX}] \\
&-\mathrm{d}\left[\mathrm{AX}^{\cdot-1+}\right] / \mathrm{d} t=2 K_{6} k_{7}\left[\mathrm{AX}^{\cdot-1+}\right]^{2}[\mathrm{AX}] \\
&-\mathrm{d}\left[\mathrm{AX}^{\cdot-1+}\right] / \mathrm{d} t=2 K_{6} K_{7} k_{8 \mathrm{a}}\left[\mathrm{AX}^{\cdot-1+}\right]^{2} \\
&-\mathrm{d}\left[\mathrm{AX}^{\cdot-1+}\right] / \mathrm{d} t=2 K_{6} K_{7} k_{8 \mathrm{~b}}\left[\mathrm{AX}^{\cdot-1+}\right]^{2}[\mathrm{Y}]
\end{aligned}
$$

It is seen that the limiting cases of the RR-mechanism give rise to rate laws that are invariably second-order in the radical ion and thus kinetically indistinguishable. For the RS-mechanism the situation is slightly different. Ratedetermining coupling, eqn. (6), gives rise to a secondorder rate law, eqn. (14), first-order in the radical ion and first-order in the substrate, whereas rate-determining electron transfer, eqn. (7), gives rise to a third-order rate law, eqn. (15), second-order in the radical ion and first order in the substrate. The rate laws (16a) and (16b) are both second-order in the radical ion.

As pointed out in Section IV, the experimental studies reported in the literature ${ }^{42-46}$ have focussed mainly on the distinction between two of these limiting cases, that is the RR-mechanism with irreversible dimerization, described by rate law (12), and the RS-mechanism with reversible coupling and irreversible electron transfer, described by rate law (15), and it is useful first to summarize the DCV and LSV response related to those two cases. (Conclusions similar to those arrived at for DCV may be obtained for other reversal techniques such as DPSC).

Reaction orders determined by $D C V$. DCV measurements for dimerization reactions are based on the determination of reaction orders through the variation of $v_{x}$ with $C(\mathrm{~A})^{\circ}$, where $v_{\mathrm{x}}$ is the voltage sweep rate necessary to keep the ratio of the derivative peak currents, $R_{\mathrm{I}}^{\prime}$, equal to $x$ (usually 0.5 ) and $C(\mathrm{~A})^{\circ}$ is the bulk concentration of the substrate. The relationship is given by eqn. (17), ${ }^{77,78}$ where $R_{\mathrm{A} / \mathrm{B}}$ is the sum of the reaction orders, $a$ and $b$, in the substrate and the radical ion, respectively, i.e., an expression of the general type: $\mathrm{d} \ln$ (rate) $/ \mathrm{d} \ln$ (concentration). ${ }^{79}$ Introduction of the reaction orders derived for the RR-mechanism with irreversible dimerization, rate law (12), and the RSmechanism with reversible coupling and irreversible electron transfer, rate law (15), in eqn. (17) results in $\mathrm{d} \log v_{1 / 2} / \mathrm{d} \log C(\mathrm{~A})^{\circ}=1$ for RR-mechanism and $\mathrm{d} \log v_{1 / 2} / \mathrm{d} \log C(\mathrm{~A})^{\circ}=2$ for the RS-mechanism.

$\frac{\mathrm{d} \log v_{1 / 2}}{\mathrm{~d} \log C(\mathrm{~A})^{\circ}}=R_{\mathrm{A} / \mathrm{B}}-1$

The application of LSV is based on measurements of the variation of the voltammetric peak potential, $E_{\mathrm{p}}$, on changes in the voltage sweep rate $(v)$ and $C(\mathrm{~A})^{\circ}$. Provided that the heterogeneous electron transfer reaction, $\mathrm{AX} \pm \mathrm{e}^{-} \rightleftharpoons \mathrm{AX}^{-/+}$, is reversible and that the process is under kinetic control ${ }^{47}$ the peak potential variations, in $\mathrm{mV} /$ decade, are given by eqns. (18)-(19). ${ }^{78}$ By introduction of the reaction orders for the same two limiting cases, rate laws (12) and (15), in eqns. (18) and (19) we have (at $298 \mathrm{~K}$ ) $\mathrm{d} E_{\mathrm{p}} / \mathrm{d} \log \mathrm{v}=-19 \mathrm{mV}$ and $\mathrm{d} E_{\mathrm{p}} / \mathrm{d} \log C(\mathrm{~A})^{\circ}=19 \mathrm{mV}$ for the RR-mechanism and $\mathrm{d} E_{\mathrm{p}} / \mathrm{d} \log v=-19 \mathrm{mV}$ and $\mathrm{d} E_{\mathrm{p}} / \mathrm{d} \log C(\mathrm{~A})^{\circ}=38 \mathrm{mV}$ for the RS-mechanism, where the signs of the slopes refer to a reduction process.

$$
\begin{aligned}
& \frac{\mathrm{d} E_{\mathrm{p}}}{\mathrm{d} \log \mathrm{v}}=\mp \frac{1}{b+1} \frac{R T}{n F} \ln 10 \\
& \frac{\mathrm{d} E_{\mathrm{p}}}{\mathrm{d} \log C(\mathrm{~A})^{\circ}}= \pm \frac{a+b-1}{b+1} \frac{R T}{n F} \ln 10
\end{aligned}
$$

Thus, it would seem to be a simple matter to distinguish between the two mechanisms by either DCV or LSV or a combination of the two techniques. However, as already mentioned the assumption of rate determining dimerization in the RR-mechanism, forward reaction (5), is not always justified. This is related to the fact that the conversion of ${ }^{-1+} \mathrm{XA}-\mathrm{AX}^{-1+}$ is often a protonation or a deprotonation reaction that under aprotic (superdry) conditions most often will have to involve a solvent component as a proton donor or acceptor and for that reason is not necessarily fast or even irreversible. In those cases the kinetic analysis also has to include the rates of the dissociation of ${ }^{-1+} \mathrm{XA}-\mathrm{AX}^{-1+}$, back reaction (5), and its further conversion, forward reaction $(8 b)$, and, if necessary, the dissociation of the product, backward reaction ( $8 \mathrm{~b})$. Here we will restrict ourselves to discussion of the case where only the irreversible formation of products apply, that is forward reaction $(8 \mathrm{~b})$, and where the bulk concentration of the reagent, $C(\mathrm{X})^{\circ}$, is much larger than $C(\mathrm{~A})^{\circ}$. Also, we will discuss only the implications of these additional reactions for the DCV response. The details related to other cases and other techniques will appear elsewhere. ${ }^{53}$

The RR-mechanism, the general case. As the starting point we will consider the DCV working curve for the RR-mechanism with irreversible dimerization, forward reaction (5). We then introduce the dissociation of the ${ }^{-1+} \mathrm{XA}-\mathrm{AX}^{-1+}$, back reaction (5), corresponding to the reversible dimerization of the radical ion, and finally we examine the additional effect of letting ${ }^{-1+} \mathrm{XA}-\mathrm{AX}^{-1+}$ in competition with dissociation, react irreversibly to products, forward reaction $(8 b)$.

The DCV working curve for irreversible dimerization obtained by digital simulation ${ }^{80}$ is shown in Fig. 22 (label (irr'). The curve has the usual S-shape observed for processes controlled by a single irreversible step with the high values of $R_{\mathrm{I}}^{\prime}$ being obtained at low values of $\log \left[k_{5} C(\mathrm{~A})^{\circ} R T /(v n F)\right]$, that is for relatively small rate constants and/or high voltage sweep rates, and the low values being obtained at high values of $\log \left[k_{5} C(\mathrm{~A})^{\circ} R T /(v n F)\right]$, that is for relatively large rate constants and/or low voltage sweep rates. Introduction of back reaction (5), here with a value of $K_{5} C(\mathrm{~A})^{\circ}=1$, results in the working curve labelled 'rev'. It is seen that the effect of the dissociation of ${ }^{-1+} \mathrm{XA}-\mathrm{AX}^{-1+}$ is only 
small as long as the value of $\log \left[k_{5} C(\mathrm{~A})^{\circ} R T /(v n F)\right]$ is less than approximately -1.5 . Thus, in this kinetic region, where ${ }^{-1+} \mathrm{XA}-\mathrm{AX}^{-1+}$ is formed only in small concentrations, the electrode response is essentially controlled by the dimerization, that is by forward reaction (5), and, accordingly, rate law (12). However, in passing gradually to larger values of $\log \left[k_{5} C(\mathrm{~A})^{\circ} R T /(v n F)\right]$, which for a given set of rate constants and a given substrate concentration corresponds to lowering the voltage sweep rate, the dissociation of ${ }^{-1+} \mathrm{XA}-\mathrm{AX}^{-1+}$ to the radical ions becomes increasingly important and as a result the working curve tends to increase again. This results in a characteristic valley, the position, depth and broadness of which depend on the magnitudes of $k_{5}$ and $K_{5}$ and thus both these parameters may be determined by fitting the working curve to the experimental data. ${ }^{32}$ Working curves similar to those shown in Fig. 22 have also been reported recently for $\mathrm{CV} .^{81}$

If now the effect of reaction ( $8 \mathrm{~b})$ is gradually introduced by allowing $k_{8 \mathrm{~b}} C(\mathrm{X})^{\circ}$ to increase from 0 , the shapes of the working curves change as illustrated in Fig. 22. The labels, ' 0 ', ' 0.01 ', ' 0.1 ' and ' 1 ' relate to the value of the parameter, $k_{8 \mathrm{~b}} C(\mathrm{X})^{\circ} / k_{-5}$, which reflects the competition between dissociation, through $k_{-5}$, and the irreversible product formation, through $k_{8 \mathrm{~b}} C(\mathrm{X})^{\circ}$. The working curves all fall between the two curves determined by irreversible and reversible dimerization, respectively, and it is characteristic that three kinetic zones may be identified as long as the value of $k_{8 \mathrm{~b}} C(\mathrm{X})^{\circ} / k_{-5}$ is not too large. Starting at low values of $\log \left[k_{5} C(\mathrm{~A})^{\circ} R T /(v n F)\right]$, that is from the left, the decreasing part of the working curves reflects, as for the working curve 'rev', a kinetic zone in which the electrode response is essentially controlled by the dimerization of the two radical ions. On passing to larger values of

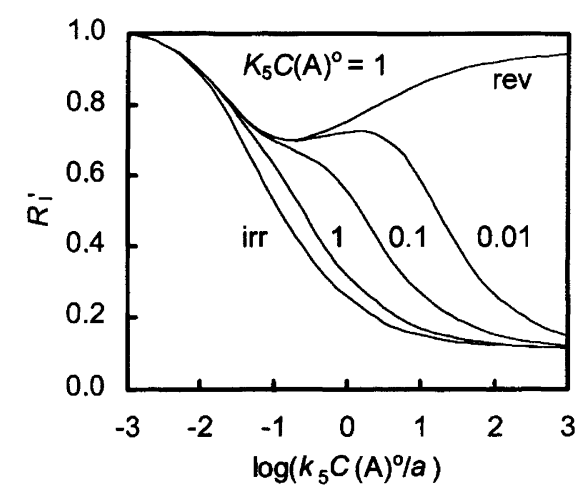

Fig. 22. Derivative cyclic voltammetry (DCV) working curves obtained by digital simulation ${ }^{80}$ for the irreversible dimerization of two radical anions [forward reaction (5)] (labeled 'irr'), the reversible dimerization of two radical ions [reversible reaction (5)] with $K_{5} C(\mathrm{~A})^{\circ}=1$ (label 'rev') and a mechanism including the reversible dimerization of two radical ions [reversible reaction (5)] with $K_{5} C(\mathrm{~A})^{\circ}=1$ followed by irreversible conversion of the doubly charged dimer into products [irreversible reaction (8b)] (labels '0.01', '0.1' and ' 1 ', where the labels refer to values of $\left.k_{8 \mathrm{~b}} C(\mathrm{X})^{\circ} / k_{-5}\right)$. The parameter, $a$, is equal to $v n F /(R T)$. $\log \left[k_{5} C(\mathrm{~A})^{\circ} R T /(v n F)\right]$ it is seen, as also for 'rev', that the working curves begin to increase again reflecting the kinetic zone in which the dissociation of ${ }^{-1+} \mathrm{XA}-\mathrm{AX}^{-1+}$ is important in determining the electrode response and, finally, at very large values of $\log \left[k_{5} C(\mathrm{~A})^{\circ} R T /(\mathrm{v} n F)\right]$ a second decreasing part is observed corresponding to the situation where the response is now essentially controlled by the conversion of ${ }^{-1+} \mathrm{XA}-\mathrm{AX}^{-1+}$ to products. In passing from $k_{8 \mathrm{~b}} C(\mathrm{X})^{\circ} / k_{-5}=0$ (corresponding to the working curve 'rev') to $k_{8 \mathrm{~b}} C(\mathrm{X})^{\circ} / k_{-5}=\infty$ (corresponding to the working curve 'irr') the reaction of ${ }^{-1+} \mathrm{XA}-\mathrm{AX}^{-1+}$ changes gradually from dissociation into irreversible conversion to products.

Inspection of the figure also shows that this second decreasing part of the working curve has essentially the same shape as the first decreasing part as long as the values of $R_{\mathrm{I}}^{\prime}$ are less than approximately 0.6. In other words, by gradually lowering the voltage sweep rate to values that give rise to $R_{\mathrm{I}}^{\prime}<0.6$ we observe a transition into the kinetic region where the rate of the reaction may be described by rate law (13b) corresponding to the limiting case defined by a fast and reversible dimerization process, characterized by $K_{5}$, followed by irreversible formation of the products, characterized by $k_{8 \mathrm{~b}} C(\mathrm{X})^{\circ}$. It should be noted here that rate law (12), corresponding to the first decreasing portion of the working curve, and rate law (13b), corresponding to the second decreasing part, are both of the same general form, $-\mathrm{d}\left[\mathrm{AX}^{\cdot-1+}\right] / \mathrm{d} t=k_{\text {obs }}\left[\mathrm{AX}^{\cdot-1+}\right]^{2}$, which is indeed the reason why these two parts of the working curve has the same shape. The horizontal displacement of the second decreasing part of the working curve, relative to that for 'irr', is determined by the magnitude of $k_{8 \mathrm{~b}} C(\mathrm{X})^{\circ} / k_{-5}$.

At this point it is important to note that a set of working curves, such as that shown in Fig. 22, except for the curve labelled 'irr', is unique for a particular value of $K_{5} C(\mathrm{~A})^{\circ}$. Thus, if we want to mimic a reaction order measurement it is necessary to examine the effect of the magnitude of $K_{5} C(\mathrm{~A})^{\circ}$ on the shape of the working curves. In order to illustrate this effect clearly we have simulated a second set of working curves similar to that in Fig. 22, but for $K_{5} C(\mathrm{~A})^{\circ}=10$, which for a given set of rate and equilibrium constants corresponds to an increase in the substrate concentration by a factor of ten. These curves are shown in Fig. 23. Owing to the second-order nature of the forward reaction (5), increasing concentrations of the substrate, and thereby of the radical ion, will cause the dimerization equilibrium to be displaced to the right. As a consequence of this, the valley becomes deeper and has its minimum located at a higher value of $\log \left[k_{5} C(\mathrm{~A})^{\circ} R T /(v n F)\right]$. Larger values of $\log \left[k_{5} C(\mathrm{~A})^{\circ} R T /(v n F)\right]$, e.g., lower sweep rates, are therefore required before the dissociation of ${ }^{-1+} \mathrm{XA}-\mathrm{AX}^{-1+}$ manifests itself as an increasing part of the working curve.

Another important consequence of the different shapes of the working curves in Figs. 22 and 23 is that a reaction order analysis based on eqn. (17) may lead to an apparent reaction order that is not related to a rate law and, 


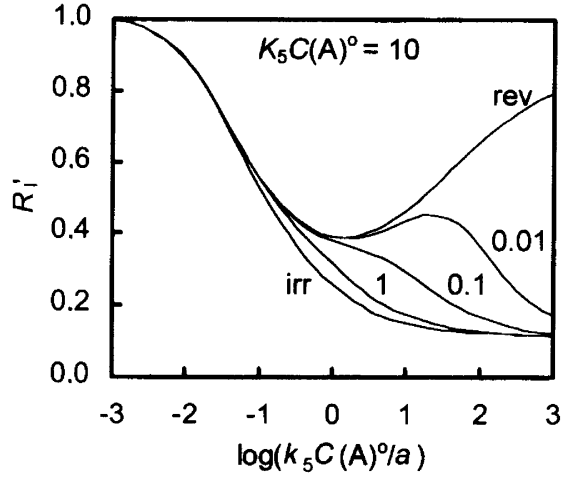

Fig. 23. Derivative cyclic voltammetry (DCV) working curves for the same mechanisms as in Fig. 22, but for $K_{5} C(A)^{\circ}=10$.

hence, cannot be used for mechanism assignment. An example will serve to illustrate this point. Let it be assumed that the reaction being studied is described by $K_{5} C(\mathrm{~A})^{\circ}=1$ and $k_{8 \mathrm{~b}} C(\mathrm{X})^{\circ} / k_{-5}=0.1$ corresponding to the working curve ' 0.1 ' in Fig. 22 . It is seen that $R_{\mathrm{I}}^{\prime}=0.5$ in this case corresponds to $\log \left[k_{5} C(\mathrm{~A})^{\circ} R T /\right.$ $(v n F)]$ equal to approximately 0.2 as indicated by the dotted line. If now the concentration of substrate is increased by a factor of ten, the appropriate working curve is the one labelled ' 0.1 ' in Fig. 23 and it is seen that $R_{\mathrm{I}}^{\prime}=0.5$ now requires that $\log \left[k_{5} C(\mathrm{~A})^{\circ} R T /(\mathrm{v} n F)\right]$ be equal to approximately -0.8 . The two-point value of $\mathrm{d} \log v_{1 / 2} / \mathrm{d} \log C(\mathrm{~A})^{\circ}$ calculated from these data is 2.0, which gives an apparent reaction order, $R_{\mathrm{A} / \mathrm{B}}$, equal to 3.0 using eqn. (17). This result would seem to be in good agreement with, e.g., the RS-mechanism with irreversible electron transfer, which gives rise to a reaction order equal to 3 , but not with the RR-mechanism with irreversible dimerization, for which the reaction order is 2 . The major origin of the problem is of course that $R_{1}^{\prime}=0.5$ at the low substrate concentration (Fig. 22) corresponds to the part of the working curve that is essentially defined by rate law (13b), whereas $R_{\mathrm{I}}^{\prime}=0.5$ at the high concentration (Fig. 23) corresponds to the part essentially defined by rate law (12). The same type of analysis carried out for $k_{8 \mathrm{~b}} C(\mathrm{X})^{\circ} / k_{-5}=0.01$ and 0.1 results in the apparent reaction orders 4.1 and 2.2 , respectively. Thus, it is easily seen that the apparent reaction order increases with decreasing values of $k_{8 \mathrm{~b}} C(\mathrm{X})^{\circ} / k_{-5}$ and therefore that virtually any value larger than 2 may result when the analysis is based on eqn. (17).

Problems of the kind just described may be difficult to detect experimentally. For example, for the reaction following the working curves ' 0.1 ' it is seen that the shape of the working curve at the low concentration (Fig. 22) is similar to that for 'irr' as long as $R_{\mathrm{I}}^{\prime}$ is lower than 0.7 and at the high concentration (Fig. 23) the same is true as long as $R_{\mathrm{I}}^{\prime}$ is higher than 0.4 . Thus, if the data for $R_{\mathrm{I}}^{\prime}$ recorded during a preliminary $\mathrm{DCV}$ investigation were all between 0.4 and 0.7 , the results would seem to indicate that the kinetics would be adequately described by a single limiting rate law. The only solution to this problem is to record the full working curves in all cases and to supply the data obtained by DCV (or DPSC) with data from LSV. An example of the latter approach is the study of the dimerization of the radical cations derived from a series of 2,5-diaryl-1,4-dithiins. ${ }^{36}$

Finally, for the sake of fairness it should be mentioned that most of the previous studies ${ }^{42-46}$ were carried out at a time where a complete analysis of the kinetics and mechanisms for radical ion dimerizations, illustrated here by just one example, would hardly have been possible for technical reasons. However, improvements in digital simulation $^{80}$ and computer speed have now made it possible to examine these important reactions in more detail.

Acknowledgements. Financial support from the Danish Natural Science Research Council (grant \#9502168) is gratefully acknowledged.

\section{References}

1. (a) Eberson, L. Electron Transfer Reactions in Organic Chemistry, Springer. Berlin 1987: (b) Eberson, L. New: J. Chem. 16 (1992) 151

2. (a) Baizer, M. M. and Lund, H., Eds., Organic Electrochemistry, an Introduction and a Guide, 3rd ed., Marcel Dekker, New York 1991; (b) Yoshida, K. Electrooxidation in Organic Chemistry, Wiley, New York 1984; (c) Torii, S. Electroorganic Syntheses, Part I: Oxidations, VCH, Weinheim 1985; (d) Shono T. Electroorganic Synthesis, Academic Press, New York 1991; (e) Fry, A. J. Synthetic Organic Electrochemistry, 2nd ed., Wiley, New York 1989.

3. (a) Fox, M. A. and Chanon, M., Eds., Photoinduced Electron Transfer, Elsevier, Amsterdam 1988; (b) Mattay, J., Ed., 'Photoinduced Electron Transfer', Top. Curr. Chem. 156 (1990); 158 (1990); 159 (1991); 163 (1992); 168 (1993); (c) Gould, I. R. and Farid, S. Acc. Chem. Res. 29 (1996) 522; (d) Kavarnos, G. J. and Turro, N. J. Chem. Rev. 86 (1986) 401 .

4. (a) Bard, A. J., Ledwith, A. and Shine, H. J. Adv. Phys. Org. Chem. 12 (1976) 155; (b) Hammerich, O. and Parker, V. D. Adv. Phys. Org. Chem. 20 (1984) 55.

5. Kochi, J. K. Adv. Free Radical Chem. 1 (1990) 53.

6. (a) Birch, A. J. and Subba Rao, G. Adv. Org. Chem. 8 (1972) 1; (b) Smith, H. Organic Reactions in Liquid Ammonia, Wiley, New York 1963.

7. (a) Eberson, L. J. Mol. Catal. 20 (1983) 27; (b) Bellville, D. J., Bauld, N. L., Pabon, R. and Gardner, S. A. J. Am. Chem. Soc. 105 (1983) 3584; (c) Bauld, N. L., Bellville, D. J., Harirchian, B., Lorenz, K. T., Pabon, R. A., Jr., Reynolds, D. W., Wirth, D. D., Chiou, H.-S. and Marsh, B. K. Acc. Chem. Res. 20 (1987) 371; (d) Bauld, N. L. Tetrahedron 45 (1989) 5307; (e) Bauld, N. L. Adv. Electron Transfer Chem. 2 (1992) 1; (f) Mizuno, K. and Otsuji, Y. Top. Curr. Chem. 169 (1994) 301.

8. (a) Bunnett, J. F. Acc. Chem. Res. 11 (1978) 413; (b) Rossi, R. A. and de Rossi, R. H. ACS Monograph 178 (1983); (c) Savéant, J. M. J. Phys. Chem. 98 (1994) 3716; (d) Amatore, C., Combellas, C., Pinson, J., Oturan, M. A., Robveille, S., Savéant, J.-M. and Thiébault, A. J. Am. Chem. Soc. 107 (1985) 4846; (e) Galli, C. and Gentili, P. Acta Chem. Scand. 52 (1998) 67.

9. (a) Eberson, L., Jönsson, L. and Wistrand, L.-G. Tetrahedron 38 (1982) 1087; (b) Kossai, R., Simonet, J. and Dauphin, G. Tetrahedron Lett. 21 (1980) 3575; (c) 
Kossai, R., Simonet, J. and Dauphin, G. J. Electroanal. Chem. 139 (1982) 207.

10. (a) Brown, O. R. and Harrison, J. A. J. Electroanal. Chem. 21 (1969) 387; (b) Holy, N. L. Chem. Rev. 74 (1974) 243; (c) Bilkis, I. I. In: Patai S., Ed., The Chemistry of Acid Derivatives, Suppl. B, Wiley, Chichester 1992, Ch. 26; (d) Kebarle, P. and Chowdhury, S. Chem. Rev. 87 (1987) 513.

11. (a) Hintz, S., Heidbreder, A. and Mattay, J. Top. Curr. Chem. 177 (1996) 77; (b) Roth, H. D., Ed., Tetrahedron 42 [Symposia-in-Print 28] (1986).

12. (a) Ridd, J. H. Acta Chem. Scand. 52 (1998) 11; (b) Sørensen, H. S. and Daasbjerg, K. Acta Chem. Scand. 52 (1998) 51; (c) Tabakovic, I., Kunugi, Y., Canavesi, A. and Miller, L. L. Acta Chem. Scand. 52 (1998) 131; (d) Dias, M., Gibson, M., Grimshaw, J., Hill, I., Trocha-Grimshaw, J. and Hammerich, O. Acta Chem. Scand. 52 (1998) 549; (e) Botzem, J., Haberl, U., Steckhan, E. and Blechert, S. Acta Chem. Scand. 52 (1998) 175; (f) Evans, D. H. Acta Chem. Scand. 52 (1998) 194; (g) Marcus, R. A. Acta Chem. Scand. 52 (1998) 858; (h) Hartshorn, M. P. Acta Chem. Scand. 52 (1998) 2; (i) Debad, J. D., Lee, S. K., Qiao, X., Pascal, R. A., Jr. and Bard, A. J. Acta Chem. Scand. 52 (1998) 45; (j) Rathore, R. and Kochi, J. K. Acta Chem. Scand. 52 (1998) 114; (k) Baciocchi, E., Bietti, M., Ferrero, M. I., Rol, C. and Sebastiani, G. V. Acta Chem. Scand. 52 (1998) 160; (1) Delaunay, J., Ghanimi, A., Diederichs, S. and Simonet, J. Acta Chem. Scand. 52 (1998) 165.

13. (a) Pross, A. J. Am. Chem. Soc. 108 (1986) 3537; (b) Shaik, S. S. and Pross, A. J. Am. Chem. Soc. 111 (1989) 4306; (c) Eberson, L., Gonzalez-Luque, R., Merchan, M., Radner, F., Roos, B. O. and Shaik, S. J. Chem. Soc., Perkin Trans. 2 (1997) 463; (d) Sastry, G. N. and Shaik, S. J. Phys. Chem. 100 (1996) 12241; (e) Reddy, A.C., Danovich, D., Ioffe, A. and Shaik, S. J. Chem. Soc., Perkin Trans. 2 (1995) 1525; (f) Shaik, S., Reddy, A. C., Ioffe, A., Dinnocenzo, J. P., Danovich, D. and Cho, J. K. J. Am. Chem. Soc. 117 (1995) 3205

14. (a) Wayner, D. D. M. and Parker, V. D. Acc. Chem. Res. 26 (1993) 287; (b) Parker, V. D. Acta Chem. Scand. 52 (1998) 145; (c) Parker, V. D. Acc. Chem. Res. 17 (1984) 243.

15. (a) Eberson, L., Hartshorn, M. P., Persson, O. and Svensson, J. O. J. Chem. Soc., Perkin Trans. 2 (1995) 1253; (b) Eberson, L., Hartshorn, M. P. and Persson, O. J. Chem. Soc., Perkin Trans. 2 (1995) 1735; (c) Eberson, L., Hartshorn, M. P., Persson, O., Radner, F. and Rhodes, C. J. J. Chem. Soc., Perkin Trans. 2 (1996) 1289; (d) Butts, C. P., Eberson, L., Hartshorn, M. P., Radner, F. and Wood, B. R. Acta Chem. Scand. 51 (1997) 476 and previous (and forthcoming) papers in this series; (e) Eberson, L., Hartshorn, M. and Radner, F. Acta Chem. Scand. 48 (1994) 937; (f) Eberson, L., Hartshorn, M. and Radner, F. Adv. Carbocation Chem. 2 (1995) 207.

16. Kaiser, E. T. and Kevan, L., Eds., Radical Ions, Wiley, New York 1968.

17. (a) Hammerich, O. and Parker, V. D. J. Electroanal. Chem. 36 (1972) App. 11; (b) Svanholm, U., Hammerich, O. and Parker, V. D. J. Am. Chem. Soc. 97 (1975) 101.

18. (a) Eberson, L., Blum, Z., Helgée, B. and Nyberg, K. Tetrahedron 34 (1978) 731; (b) Eberson, L. and Nyberg, K. Acta Chem. Scand., Ser. B 32 (1978) 235.

19. (a) Fussing, I., Güllü, M., Hammerich, O., Hussain, A., Nielsen, M. F. and Utley, J. H. P. J. Chem. Soc., Perkin Trans. 2 (1996) 649; (b) Nielsen, M. F. and Hammerich, O. Unpublished results; (c) Fussing, I., Hammerich, O., Hussain, A., Nielsen, M. F. and Utley, J. H. P. Acta Chem. Scand. 52 (1998) 325.

20. Klemm, L. H. and Olson, D. R. J. Org. Chem. 38 (1973) 3390.
21. Smith, C. Z. and Utley, J. H. P. J. Chem. Soc., Chem. Commun. (1981) 492.

22. Utley, J. H. P., Güllü, M. and Motevalli, M. J. Chem. Soc., Perkin Trans. 1 (1995) 1961.

23. Parker, V. D. Acta Chem. Scand., Ser. B 35 (1981) 147.

24. (a) Nielsen, M. F. and Hammerich, O. Acta Chem. Scand. 46 (1992) 883; (b) Mendkovich, A. S., Hammerich, O., Rubinskaya, T. Ya., and Gultyai, V. P. Acta Chem. Scand. 45 (1991) 644; (c) Nielsen, M. F., Eggert, H. and Hammerich, O. Acta Chem. Scand. 45 (1991) 292; (d) Nielsen, M. F. and Hammerich, O. Acta Chem. Scand. 43 (1989) 269; (e) Nielsen, M. F. and Hammerich, O. Acta Chem. Scand., Ser. B 41 (1987) 668; (f) Nielsen, M. F., Hammerich, O. and Parker, V. D. Acta Chem. Scand., Ser. $B 41$ (1987) 50; (g) Nielsen, M. F., Porat, Z., Eggert, H. and Hammerich, O. Acta Chem. Scand., Ser. B 40 (1986) 652; 41 (1987) 156; (h) Nielsen, M. F., Hammerich, O. and Parker, V. D. Acta Chem. Scand., Ser. B 40 (1986) 101; (i) Nielsen, M. F., Batanero, B., Löhl, T., Schäfer, H. J., Wüthwein, E. U. and Fröhlich, R. Chem. Eur. J. 3 (1997) 2011; (j) Nielsen, M. F., Spriggs, S., Utley, J. H. P. and Gao, Y. J. Chem. Soc., Chem. Commun. (1994) 1395; (k) Bettencourt, A.-P., Freitas, A. M., Montenegro, M. I., Nielsen, M. F. and Utley, J. H. P. J. Chem. Soc., Perkin Trans. 2 (1998) 515.

25. Parker, V. D. Acta Chem. Scand., Ser. B 35 (1981) 295.

26. Hammerich, O. and Parker, V. D. In: Baizer, M. M. and Lund, H., Eds. Organic Electrochemistry, an Introduction and a Guide, 3rd ed., Marcel Dekker, New York 1991, Ch. 3.

27. Nielsen, M. F. Lecture at the 14th International Conference on Radical Ions, July 1996, Uppsala, Sweden.

28. Dewar, M. J. S., Zoebisch, E. G., Healy, E. F. and Stewart, J. J. P. J. Am. Chem. Soc. 107 (1985) 3902.

29. Zoutendam, P. H. and Kissinger, P.T. J. Org. Chem. 44 (1979) 758 .

30. Kimura, M., Moritani, N. and Sawaki, Y. Electroorg. Synth., M.M. Baizer Mem. Symp., Dekker, New York 1991, p. 61.

31. Zuman, P. Substituent Effects in Organic Polarography, Plenum Press, New York 1967.

32. (a) Hammerich, O. and Parker, V. D. Acta Chem. Scand., Ser. B 35 (1981) 341; (b) Hammerich, O. and Parker. V. D. Acta Chem. Scand., Ser. B 37 (1983) 379; (c) Eliason, R., Hammerich, O. and Parker, V. D. Acta Chem. Scand., Ser. B 42 (1988) 7 .

33. (a) Mendkovich, A. S., Michalchenko, L. V. and Gultyai, V. P. J. Electroanal. Chem. 224 (1987) 273; (b) Smith, C. Z. and Utley, J. H. P. J. Chem. Res. (S) (1982) 18; (c) Yildiz, A. and Baumgärtel, H. Ber. Bunsenges. Phys. Chem. 81 (1977) 1177; (d) Oturan, N. A. and Yildiz, A. J. Electroanal. Chem. 161 (1984) 377; (e) Amatore, C., Pinson, J. and Savéant, J. M. J. Electroanal. Chem. 137 (1982) 143; (f) Amatore, C., Pinson, J. and Savéant, J. M. J. Electroanal. Chem. 139 (1982) 193; (g) Amatore, C., Garreau, D., Hammi, M., Pinson, J. and Savéant, J. M. J. Electroanal. Chem. 184 (1985) 1.

34. Hazelrigg, M. J. and Bard, A. J. J. Electrochem. Soc. 122 (1975) 211.

35. Yeh, L.-S. R. and Bard, A. J. J. Electrochem. Soc. 124 (1977) 355 .

36. Andersen, M. L., Nielsen, M. F. and Hammerich, O. Acta Chem. Scand. 51 (1997) 94.

37. (a) Johnston, L. J. and Schepp, N. P. J. Am.Chem. Soc. 115 (1993) 6564; (b) Workentin, M. S., Schepp, N. P., Johnston, L. J. and Wayner, D. D. M J. Am. Chem. Soc. 116 (1994) 1141; (c) Schepp, N. P. and Johnston, L. J. J. Am. Chem. Soc. 116 (1994) 10330; (d) Johnston, L. J. and Schepp, N. P. Pure Appl. Chem. 67 (1995) 71; (e) Schepp, N. P. and Johnston, L. J. J. Am. Chem. Soc. 118 
(1996) 2872; (f) Schepp, N. P. and Johnston, L. J. J. Am. Chem. Soc. 116 (1994) 6895.

38. (a) Reitstöen, B. and Parker, V. D. J. Am. Chem. Soc. 113 (1991) 6954; (b) Parker, V. D., Pedersen, M. and Reitstöen B. Acta Chem. Scand. 47 (1993) 560.

39. Creason, S. C., Wheeler, J. and Nelson, R. F. J. Org. Chem. 37 (1972) 4440.

40. Schäfer, H. J. Angew. Chem. 93 (1981) 978.

41. (a) Pletcher, D. and Walsh, F. C. Industrial Electrochemistry, 2nd ed., Chapman and Hall, London 1990; (b) Baizer, M. M. In: Baizer, M. M. and Lund, H., Eds. Organic Electrochemistry, an Introduction and a Guide, 3rd ed., Marcel Dekker, New York 1991, Ch. 10.

42. (a) Nadjo, L., Savéant, J.-M. and Tessier, D. J. Electroanal. Chem. 64 (1975) 143; (b) Nadjo, L. and Savéant, J.-M J. Electroanal. Chem. 73 (1976) 163; (c) Amatore, C. and Savéant, J. M. J. Electroanal. Chem. 144 (1983) 59.

43. (a) Aalstad, B., Ronlán, A. and Parker, V. D. Acta Chem. Scand., Ser. B 35 (1981) 247; (b) Aalstad, B., Ronlán, A. and Parker, V. D. Acta Chem. Scand., Ser. B 35 (1981) 649; (c) Lerflaten, O., Parker, V. D. and Margaretha, P. Monatsh. 115 (1984) 697; (d) Parker, V. D. Acta Chem. Scand., Ser. B 35 (1981) 149; (e) Parker, V. D. Acta Chem. Scand., Ser. B 35 (1981) 279; (f) Margaretha, P. and Parker, V. D. Acta Chem. Scand., Ser. B 36 (1982) 260 (g) Margaretha, P. and Parker, V. D. Chem. Lett. (1984) 681; (h) Aalstad, B., Ronlán, A. and Parker, V. D. Acta Chem. Scand., Ser. B 36 (1982) 171: (i) Parker, V. D. Acta Chem. Scand. 52 (1998) 154.

44. Nozaki, K., Oyama, M., Hatano, H. and Okazaki, S. J. Electroanal. Chem. 270 (1989) 191.

45. Gennaro, A., Romanin, A. M., Severin, M. G. and Vianello, E. J. Electroanal. Chem. 169 (1984) 279.

46. Zhou, F. and Bard, A. J. J. Am. Chem. Soc. 116 (1994) 393.

47. Nadjo, L. and Savéant, J. M. J. Electroanal. Chem. 44 (1973) 327.

48. (a) Hammerich, O. and Parker, V. D. Acta Chem. Scand., Ser. B 37 (1983) 851; (b) Houser, K. J., Bartak, D. E. and Hawley, M. D. J. Am. Chem. Soc. 95 (1973) 6033; (c) Koppang, M. D., Woolsey, N. F. and Bartak, D. E. J. Am. Chem. Soc. 107 (1985) 4692.

49. Rainis, A. and Szwarc, M. J. Phys. Chem. 79 (1975) 106.

50. (a) Eberson, L., Utley, J. H. P. and Hammerich, O. In: Baizer, M. M. and Lund, H., Eds., Organic Electrochemistry, an Introduction and a Guide, 3rd ed. Marcel Dekker, New York 1991, Ch. 13; (b) Hammerich, O. and Svensmark, B. In: Baizer, M. M. and Lund, H. Eds., Organic Electrochemistry, an Introduction and a Guide, 3rd ed., Marcel Dekker, New York 1991, Ch. 16.

51. Ronlán, A., Hammerich, O. and Parker, V. D. J. Am. Chem. Soc. 95 (1973) 7132.

52. Aalstad, B., Ronlán, A. and Parker, V. D. Acta Chem. Scand., Ser. B 36 (1982) 199.

53. Nielsen, M. F. and Hammerich, O. Manuscript in preparation.

54. Hammerich, O. and Parker, V. D. Electrochim. Acta 18 (1973) 537.

55. (a) Schmittel, M., Wöhrle, C. and Bohn, I. Acta Chem. Scand. 51 (1997) 151; (b) Simonet, J., Delaunay, J., Orliac-Le Moing, M.-A. and Toupet, L. New J. Chem. 14 (1990) 849; (c) Jones, G. II, Becker, W. G. and Chiang, S.-H. J. Am. Chem. Soc. 105 (1983) 1269; (d) Mattes, S. L. and Farid, S. Acc. Chem. Res. 15 (1982) 80 and references cited therein; (e) Cedheim, L. and Eberson, L. Acta Chem. Scand., Ser. B 30 (1976) 527; (f) Ledwith, A. Acc. Chem. Res. 5 (1972) 133 and references cited therein.

56. (a) Delaunay, J., Mabon, G., Orliac-Le Moing, A. and Simonet, J. Tetrahedron Lett. 31 (1990) 667; (b) Delaunay, J., Orliac-Le Moing, A. and Simonet, J. New J. Chem. 17
(1993) 393; (c) Janssen, R. G., Motevalli, M. and Utley, J. H. P. J. Chem. Soc., Chem. Commun. In press.

57. (a) Klopman, G. J. Am. Chem. Soc. 90 (1968) 223; (b) Klopman, G. In: Chemical Reactivity and Reaction Paths, Klopman, G., Ed., Wiley, New York 1974, Ch. 4.

58. (a) Mendkovich, A. S. and Gultyai, V. P. J. Electroanal. Chem. 169 (1984) 1; (b) Mendkovich, A. S. and Rusakov, A. I. J. Electroanal. Chem. 209 (1986) 43.

59. (a) Rainis, A., Tung, R. and Szwarc, M. Proc. R. Soc., London, Ser. A 339 (1974) 417; (b) Minnich, E. R., Long, L. D., Ceraso, J. M. and Dye, J. L. J. Am. Chem. Soc. 95 (1973) 1061; (c) Rainis, A., Tung, R. and Szwarc, M. J. Am. Chem. Soc. 95 (1973) 659; (d) Levin, G., Sutphen, C. and Szwarc, M. J. Am. Chem. Soc. 94 (1972) 2652; (e) Szwarc, M. Acta Chem. Scand. 51 (1997) 529; (f) Szwarc, M. In: Mamantov, G., Ed., Characterization of Solutes in Nonaqueous Solvents, Plenum Press, New York 1978, Ch. 5.

60. (a) Vincent, M. L. and Peters, D. G. J. Electroanal. Chem. 324 (1992) 93; (b) Farnia, G., Marcuzzi, F., Melloni, G. and Sandonà, G. J. Am. Chem. Soc. 106 (1984) 6503; (c) Farnia, G., Maran, F., Sandonà, G. and Severin, M. G. J. Chem. Soc., Perkin Trans. 2 (1982) 1153; (d) Farnia, G., Maran, F. and Sandonà, G. J. Chem. Soc., Faraday Trans. 1, 82 (1986) 1885 .

61. (a) Streitweiser, A. Jr. and Suzuki, S. Tetrahedron 16 (1961) 153; (b) Fry, A. J. and Schuettenberg, A. J. Org. Chem. 39 (1974) 2452; (c) Harvey, R. G., Lindow. D. F. and Rabideau. P. W. J. Am. Chem. Soc. 94 (1972) 5412; (d) Harvey, R. G., Arzadon, L., Grant, J. and Urberg, K. J. Am. Chem. Soc. 91 (1969) 4535; (e) Zimmerman, H. E. Tetrahedron 16 (1961) 169.

62. (a) Cramer, C. J. and Truhlar, D. G. J. Am. Chem. Soc. 113 (1991) 8305; (b) Dixon, R. W., Leonard, J. M. and Hehre, W. J. Is. J. Chem. 33 (1993) 427; (c) Guerra, M., Bernardi, F. and Pedulli, G. F. Chem. Phys. Lett. 81 (1981) 289.

63. Szabo, A. and Ostlund, N. S. Modern Quantum Theory, Dover, Mineola 1996.

64. (a) Maccoll, A. Nature 163 (1949) 178; (b) Streitweiser, A. Jr. Molecular Orbital Theory for Organic Chemists, Wiley, New York 1961; (c) Hoijtink, G. J. and Van Schooten, J. Recl. Trav. Chim. 71 (1952) 1089; (d) Hoijtink, G. J. and Van Schooten, J. Recl. Trav. Chim. 72 (1953) 691.

65. (a) Parker, V. D. J. Am. Chem. Soc. 98 (1976) 98; (b) Dewar, M. J. S., Hashmall, J. A. and Trinajstić, N. J. Am. Chem. Soc. 92 (1970) 5555.

66. Tanner, D. D., Deonarian, N., Kharrat, A. Can. J. Chem. 67 (1989) 171.

67. Dewar, M. J. S. and Rzepa, H. S. J. Am. Chem. Soc. 100 (1978) 784.

68. Crocker, L., Wang, T. and Kebarle, P. J. Am. Chem. Soc. 115 (1993) 7818.

69. Wayner, D. D. M., Sim, B. A. and Dannenberg, J. J. J. Org. Chem. 56 (1991) 4853.

70. Dewar, M. J. S., Jie, C. and Yu, J. Tetrahedron 49 (1993) 5003.

71. (a) Hehre, W. J., Radom, L. and Pople, J. A. J. Am. Chem. Soc. 94 (1972) 1496; (b) Birch, A. J., Hinde, A. L. and Radom, L. J. Am. Chem. Soc. 102 (1980) 3370; (c) Birch, A. J., Hinde, A. L. and Radom, L. J. Am. Chem. Soc. 102 (1980) 4074.

72. (a) Maslak, P. and Guthrie, R. D. J. Am. Chem. Soc. 108 (1986) 2628; (b) Maslak, P. and Guthrie, R. D. J. Am. Chem. Soc. 108 (1986) 2637.

73. Andersen, M. L., Mathivanan, N. and Wayner, D. D. M. J. Am. Chem. Soc. 118 (1996) 4871.

74. (a) Dougherty, D. A., Choi, C. S., Kaupp, G., Buda, A. B., Rudzinski, J. M. and Osawa, E. J. Chem. Soc., Perkin Trans. 2 (1986) 1063; (b) Barber, R. A., de Mayo, P., 
Okada, K. and Wong, S. K. J. Am. Chem. Soc. 104 (1982) 4995.

75. Hammerich, O. and Nielsen, M. F. Work in progress.

76. Nielsen, M. F. and Hammerich, O. Work in progress.

77. (a) Parker, V. D. Acta Chem. Scand., Ser. B 35 (1981) 259;

(b) Parker, V. D. Acta Chem. Scand., Ser. B 38 (1984) 165;

(c) Parker, V. D. In: Fry, A. J. and Britton, W. E., Eds., Topics in Organic Electrochemistry, Plenum, New York 1986, Ch. 2.
78. Parker, V. D. Electroanal. Chem. 14 (1986) 1.

79. King, E. L. J. Chem. Educ. 51 (1974) 186.

80. (a) Rudolph, M. J. Electroanal. Chem. 314 (1991) 13; (b) Rudolph, M. In: Rubinstein, I., Ed., Physical Electrochemistry, Marcel Dekker, New York 1995, Ch. 3.

81. Tschuncky, P., Heinze, J., Smie, A., Engelmann, G. and Koßmehl, G. J. Electroanal. Chem. 433 (1997) 223.

Received December 12, 1997. 